\title{
Is there a link between economic outcomes and genetic evolution? Cross-country evidence from the Major Histocompatibility Complex
}

Citation for published version (APA):

Borghans, J. A. M., Borghans, L., \& ter Weel, B. J. (2005). Is there a link between economic outcomes and genetic evolution? Cross-country evidence from the Major Histocompatibility Complex. UNU-MERIT, Maastricht Economic Research Institute on Innovation and Technology. MERIT-Infonomics Research Memorandum Series No. 029 https://doi.org/10.26481/umamer.2005029

Document status and date:

Published: 01/01/2005

DOI:

10.26481/umamer.2005029

Document Version:

Publisher's PDF, also known as Version of record

Please check the document version of this publication:

- A submitted manuscript is the version of the article upon submission and before peer-review. There can be important differences between the submitted version and the official published version of record.

People interested in the research are advised to contact the author for the final version of the publication, or visit the DOI to the publisher's website.

- The final author version and the galley proof are versions of the publication after peer review.

- The final published version features the final layout of the paper including the volume, issue and page numbers.

Link to publication

\footnotetext{
General rights rights.

- You may freely distribute the URL identifying the publication in the public portal. please follow below link for the End User Agreement:

www.umlib.nl/taverne-license

Take down policy

If you believe that this document breaches copyright please contact us at:

repository@maastrichtuniversity.nl

providing details and we will investigate your claim.
}

Copyright and moral rights for the publications made accessible in the public portal are retained by the authors and/or other copyright owners and it is a condition of accessing publications that users recognise and abide by the legal requirements associated with these

- Users may download and print one copy of any publication from the public portal for the purpose of private study or research.

- You may not further distribute the material or use it for any profit-making activity or commercial gain

If the publication is distributed under the terms of Article $25 \mathrm{fa}$ of the Dutch Copyright Act, indicated by the "Taverne" license above, 


\section{MERIT-Infonomics Research Memorandum series}

Is There a Link between Economic Outcomes and Genetic Evolution? Cross-Country Evidence from the Major Histocompatibility Complex

José Borghans, Lex Borghans \& Bas ter Weel

2005-029

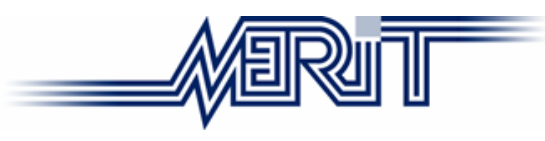

MERIT - Maastricht Economic Research Institute on Innovation and Technology

PO Box 616

6200 MD Maastricht

The Netherlands

$\mathrm{T}:+31433883875$

F: +31433884905

http://www.merit.unimaas.nl e-mail:secr-merit@merit.unimaas.nl

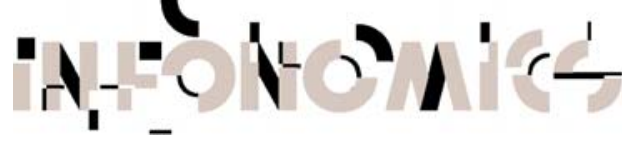

International Institute of Infonomics

c/o Maastricht University PO Box 616

6200 MD Maastricht

The Netherlands

T: +31 433883875

F: +31 453884905

http://www.infonomics.nl

e-mail: secr@infonomics.nl 


\title{
Is There a Link between Economic Outcomes and Genetic Evolution? Cross-Country Evidence from the Major Histocompatibility Complex*
}

\author{
José A.M. Borghans \\ Department of Immunology, Wilhelmina Children's Hospital, UMCU, the Netherlands \\ j.borghans@umcutrecht.nl \\ Lex Borghans \\ ROA, Maastricht University, the Netherlands \\ l.borghans@roa.unimaas.nl \\ Bas ter Weel \\ Department of Economics and MERIT, Maastricht University, the Netherlands \\ b.terweel@merit.unimaas.nl
}

28 October 2005

\begin{abstract}
This research develops a theory and presents empirical evidence of a link between economic outcomes and genetic evolution. Important properties for successful analysis of such a link are found in the adaptive immune system and particularly in the major histocompatibility complex (MHC), a genetically encoded complex involved in the defence against infections. The theory incorporates properties of the MHC in a model of mutual dependence and exhibits a trade-off in which every agent who is better off having an immune response different from that of others is also part of the protecting belt of others in a population, in which mounting similar immune responses is optimal. The data are based on large numbers of blood samples from 63 different populations. The cross-country estimates show a robust negative association between economic and health outcomes and MHC diversity and between average offers in ultimatum and trust games and MHC diversity. The analyses suggest that societies incorporating externalities from mutual dependence are economically more successful, and that the incorporation of such externalities is evident at the gene level.
\end{abstract}

${ }^{*}$ We would like to thank Loes van Driel for excellent research assistance. We wish to thank seminar participants at De Nederlandsche Bank, the Evolution and Behavior Workshop in Maastricht, the Growth Conference in Lucca, Hebrew University, IZA, MERIT, the NBER Summer Institute, and Daron Acemoglu, Philippe Aghion, Josh Angrist, Rob de Boer, Arnaud Dupuy, Oded Galor, Moshe Hazan, Francis Kramarz, Nils-Petter Lagerlöf, Erzo Luttmer, Omer Moav, Ido Pen, Gilles Saint-Paul, Mathias Thoenig, Adriaan van Zon, Simon Verhulst, David Weil, Franjo Weissing, and Thomas Ziesemer for useful comments, and Ella van den Berg-Loonen and Christina Voorter of the Tissue Typing Laboratory at the University Hospital in Maastricht for clarifying measurement issues. We are grateful to the Netherlands Organisation for Scientific Research (NWO) for financial support. 


\section{Introduction}

This paper develops a theory and presents evidence of a link between economic achievement and genetic evolution. We argue that economic conditions are a crucial determinant of genetic evolution and give an explanation of how evolutionary forces have favored human characteristics that are well-adapted to economic circumstances. When populations are exposed to distinct economic conditions, they develop in dissimilar ways, so genetic differences can reveal divergent economic circumstances in a population. If these economic conditions also affect economic outcomes a link can be established. The main obstacle to investigate the link between genetic evolution and economic outcomes is to select genes for which a relationship with economic circumstances can be obtained. ${ }^{1}$ There are three crucial conditions for this research to be successful: (i) the genes studied have to be of eminent importance for evolutionary success; (ii) the genes' fitness has to change with economic circumstances; and (iii) the genes' evolution has to keep abreast of changes in economic circumstances. ${ }^{2}$

We investigate genes that encode the major histocompatibility complex (MHC), in humans defined as the human leukocyte antigen (HLA), and argue that these genes satisfy the three conditions mentioned above. First, the MHC encodes a set of closely linked genetic loci that play a crucial role in the adaptive immune system. The basic role of the $\mathrm{MHC}$ is to help control infectious diseases. ${ }^{3}$ Because of its crucial role in the immune system it is subject to strong evolutionary pressure.

Second, the MHC is the most polymorphic gene known. Despite the strong evolutionary pressure different MHC molecules do not outperform each other, which suggests frequency dependent selection in which agents benefit from having rare molecules. However, MHC diversity turns out to be limited because the distribution of MHC molecules is far from uniform and a small number of MHC molecules are observed at a relatively high frequency. In addition, the observed frequency distributions differ strongly between different populations. We argue that these frequency distributions reflect economic circumstances with two forces working in opposite directions. On the one hand, since agents are most likely infected through contact with others, individuals expressing a rare type of MHC molecule have a selective advantage. On the other hand, we show that simi-

\footnotetext{
${ }^{1}$ Research has only pointed to a theoretical link between economic and evolutionary forces. The economic literature has studied a number of human characteristics important for economic behavior and success, which are potentially subject to evolutionary selection (e.g., altruism and reciprocity). Also differences in preferences (e.g., discount rates and quantityquality trade-offs for children) have been linked to genetic evolution. However, empirical linkages of these theoretical notions are hampered by a lack of knowledge about the actual genes related to these human characteristics and economic outcomes.

${ }^{2}$ There are two recent fields of empirical literature using biological information to understand human behavior in economic environments, but these studies do not study genetic evolution. There is recent literature on neuroeconomics (e.g., Dolan [2002] and Camerer [2003] for reviews) mainly studying economic rationality; and Kosfeld et al. [2005] have shown that oxytocin increases an agent's willingness to accept social risks in trust games.

${ }^{3}$ Basically the MHC presents pathogen parts to the cell membrane, which triggers the growth of $\mathrm{T}$ cells which eliminate the infection. See Hansen and Sachs [1989] for an overview study of the role of the MHC in the adaptive immune system.
} 
larity of the adaptive immune system is advantageous from the perspective of a group of agents. This trade-off between the individual's and society's optimum level of genetic diversity presents an externality suggesting that the equilibrium with the maximum level of diversity is not necessarily optimal.

Third, a change in the observed frequency of existing MHC molecules in a population suffices to change the population's genetic diversity. The advantage of this property is that only a fraction of the population with certain MHC molecules needs to change to induce changes in diversity. In addition, the characteristics that need to change are already present in the population and do not require mutation and suppression of previously dominant genes. Rapid evolutionary processes are observed and simulated, requiring only a couple of generations for substantial adjustments in the level of MHC diversity of populations.

To understand the link between economic performance and the MHC we model the role of $\mathrm{MHC}$ in the protection against pathogens. First we analyze the evolutionary stable equilibrium with selfish agents, and then analyze the equilibrium when agents cooperate. We define cooperation as mutual dependence resulting from working together in small groups in which agents equally share the resulting output from joint production. We model this in terms of a public-good game in which defection is punished. Agents contracting a disease are out of the production process for some time to recover. A key feature of the model is that income depends more on the performance of others if the agent cooperates more. Assuming that evolutionary success is positively correlated with income, agents in more cooperative societies have more interest in the health of the agents they cooperate with. If agents are not interested in cooperation they do not care about the health of others and benefit from a deviant immune system. The resulting distribution of $\mathrm{MHC}$ molecules will be uniform. If the risk of transmitting a disease depends sufficiently on the MHC molecule of an agent, and the size of the groups in which agents are working cooperatively is large enough, the social optimum (in which the number of infectious diseases in a population is minimized) does not equal the evolutionary stable equilibrium. In such cases a lower level of MHC diversity is more beneficial for the health outcomes of a population. Finally, we show that when people are more cooperative the evolutionary stable equilibrium will be closer to the the social optimum. In such an equilibrium the more agents depend on joint production the more selective advantages they will experience from molecules that reduce the number of infections of group members. In this cooperative setting the model is able to generate frequency distributions that correspond to the actual observed distributions within populations.

Assuming that there are persistent differences in cooperative behavior between populations ${ }^{4}$ those with higher levels of cooperation exhibit lower equilibrium levels of $\mathrm{MHC}$

\footnotetext{
${ }^{4}$ See e.g., Roth et al. [1991], Henrich et al. [2001], Charness and Rabin [2002], and Fehr and Fishbacher [2003] for
} 
diversity which improves the health status of the population. As a consequence, if cooperation also enhances economic performance, there will be a negative correlation between economic performance and MHC diversity. ${ }^{5}$

In the empirical analysis we use information about HLA-A and HLA-B molecules because these are the HLA types for which most data are available from different populations (details about the advantages of using $\mathrm{A}$ and $\mathrm{B}$ molecules are given below). ${ }^{6}$ Based on HLA data from a large number of individuals from different populations we construct a sample of 63 populations to investigate three different relationships. First, cooperation leads to mutual dependence and the health of others will be internalized, so we expect a negative correlation between measures of cooperation and $\mathrm{MHC}$ diversity. We correlate MHC diversity with the offer rates in ultimatum games and amounts of money sent in trust games, collected from a number of studies conducted for different countries, and find a strong negative relationship between MHC diversity and these measures of cooperation. This is consistent with the prediction of the model that in more trusting societies the adaptive immune system is more homogenous. Second, a discrepancy between the selfish stable evolutionary equilibrium and the social optimum should be associated with a negative correlation between MHC diversity and health outcomes. The main reason for this is that in societies with higher levels of mutual dependence MHC diversity is lower and the health status of agents better. Using life expectancy at birth and the fraction of people dying from viral infections as indicators of health we find a robust negative correlation between HLA-A and HLA-B diversity and health outcomes. Finally, societies that are better able to cope with public-good dilemmas will be economically more successful. More cooperation induces lower optimal levels of MHC diversity, so we expect a negative correlation between $\mathrm{MHC}$ diversity and economic performance. The estimates show a robust negative correlation between HLA-A and HLA-B diversity and economic outcomes.

The paper proceeds as follows. Section 2 presents the MHC properties important for economic outcomes and the data. Section 3 presents the model and the evolutionary equilibrium outcomes. Section 4 presents the empirical results of the correlation between measures of human cooperation and MHC diversity, the relationship between life expectancy and MHC diversity, and the relationship between economic outcomes and MHC diversity. Section 5 discusses a number of alternative explanations. Section 6 concludes.

\footnotetext{
studies obtaining differences in ultimatum game offer rates across populations, cities and countries.

${ }^{5}$ Saint-Paul [2003] and Galor and Moav [2004] also explicitly model genetic differences. Saint-Paul develops a theory of comparative advantage to show that under trade less fit humans are able to survive and to be as productive as fitter humans. Galor and Moav argue that increased pathogen pressure, worsened living conditions and environmental hazards in the movement from hunter-gatherer societies to agricultural societies reduced life expectancy initially, but at the same time selected individuals who were less vulnerable to this movement, which eventually increased life expectancy. However, these contributions do not offer empirical support for a direct link between economic performance and genetic evolution.

${ }^{6}$ There are six different types of HLA molecules. For the other HLA types (HLA-C, HLA-DP, HLA-DQ and HLA-DR) much less data are available from many populations.
} 


\section{The Major Histocompatibility Complex}

Immunology is concerned with the means by which a host tries to control infectious diseases caused by pathogens. ${ }^{7}$ Protection against pathogens operates at three different levels. First, external defences, such as the skin, hamper the intrusion of pathogens. Second, if pathogens nevertheless manage to enter the host, the innate immune system rapidly tries to eliminate them using a large variety of cells and molecules. Finally, if pathogens are not captured and disposed by the innate immune system, the adaptive immune system, consisting of a huge diversity of lymphocytes, eliminates the pathogen (whenever possible) and retains immunological memory to be protected against future infections with the same pathogen.

In mammalians and many other species a set of closely linked genetic loci is of fundamental importance for the adaptive immune system. This set of genes encodes the major histocompatibility complex (MHC). MHC molecules play a crucial role in the induction of $\mathrm{T}$ lymphocytes of the adaptive immune system. ${ }^{8}$ Its basic role is to present pathogens to the adaptive immune system. ${ }^{9}$

\subsection{The Basic Role of MHC in the Immune System}

A pathogen that has managed to infect a host, and has escaped the external defence and the innate immune system, may be harmful to the host. In case of a viral infection, infected cells become the producers of new pathogens. The cell decomposes its intracellular proteins, including the viral proteins, into short peptides. ${ }^{10}$ The primary role of MHC molecules is to take small samples from these large collections of peptides and present these peptides on the cell membrane. In response to the presentation of foreign peptides on the cell membrane, the activity and proliferation of specialist T cells is triggered, which ultimately leads to killing of the infected cell. Thus, the presence of a foreign peptide bound to an MHC molecule signals the presence of a foreign pathogen inside the cell. After a while the proliferation of $\mathrm{T}$ cells stops and most $\mathrm{T}$ cells die. About 5-10 percent of the specific $\mathrm{T}$ cells survive and form a population of "memory cells" responsible for future protection. ${ }^{11}$

\footnotetext{
${ }^{7}$ Pathogens are defined as infectious agents that cause diseases. Microbiologists generally distinguish six classes of pathogens: viruses (e.g., pox, and influenza), bacteria (e.g., syphilis and tuberculosis), fungi (e.g., ringworm and yeast), protozoa (e.g., trypanosome), helminths (e.g., hookworm and tapeworm) and ectoparasites (insects).

${ }^{8}$ The adaptive immune system itself consists of B lymphocytes, which produce antibodies, and T lymphocytes. There are two major types of T lymphocytes: cytotoxic T lymphocytes (CTL), which kill pathogens, and helper T lymphocytes, which play a central role in the induction of $\mathrm{B}$ and $\mathrm{T}$ lymphocyte responses.

${ }^{9}$ Playfair and Bancroft [2004] review the study of infection and immunity at great length.

${ }^{10}$ For class I MHC molecules short means that these peptides consist of 8-11 amino acids only.

${ }^{11} \mathrm{~T}$ cells have similarities with B cells, which produce antibodies, but there are important differences. While B cells can directly recognize extracellular pathogens, $\mathrm{T}$ cells only recognize peptides that are being presented by MHC molecules on the surface of cells. T cells can be thought of as hands reaching out to feel the surface of neighboring cells, with some fingers contacting the MHC molecules and others probing for the peptide bound to them. Pathogens that survive inside host cells are thus effectively protected against recognition by B cells, but the MHC molecules betray their presence to T cells.
} 
Figure Ia provides a schematic representation of an MHC molecule. The polymorphic pair at the top of the molecule $\left(\alpha_{1}\right.$ and $\left.\alpha_{2}\right)$ forms a groove to which peptides are bound. The specific binding properties of different MHC molecules determine which peptides are presented to the $\mathrm{T}$ cells and, as a result, which parts of a pathogen are recognized by the immune system. This means that different individuals with different MHC molecules sample different peptides from the same set of proteins to initiate an immunological response to an infection. This can explain differences in disease progression between individuals, as has been shown for HIV (Carrington and O'Brien [2003]) and malaria (Hill et al. [1991]).

Figure Ib illustrates how T cells cooperate with MHC molecules to kill a virally infected cell. Once the cell has been infected, the MHC molecules on the cell surface present peptides, which can be recognized as foreign by specialist $\mathrm{T}$ cells. If a $\mathrm{T}$ cell recognizes a peptide-MHC complex it is able to respond effectively to the infection and to eventually kill the virally infected cell.

In humans, human leukocyte antigens (HLA) are encoded by genes located on chromosome 6. Six different types of HLA molecules are distinguished: HLA-A, HLA-B, and HLA-C are class I MHC molecules and are found on the membrane of every body cell, while HLA-DP, HLA-DQ, and HLA-DR are class II MHC molecules and are present only on the membrane of certain cells of the immune system. HLA-A, HLA-B, and HLA-C are especially important for immune responses against intracellular pathogens (such as viruses), while HLA-DP, HLA-DQ, and HLA-DR are mainly deployed to control extracellular infections (such as many bacterial infections). MHC class I molecules trigger so-called cytotoxic T lymphocytes, while MHC class II molecules induce $\mathrm{T}$ helper responses.

The MHC is known for its remarkable degree of polymorphism. In mammalians MHC genes are the most polymorphic genes present, so that within a population many different alleles per MHC locus exist. ${ }^{12}$ Since MHC molecules fulfil a crucial role in the host's immune response to pathogens, there is strong evolutionary selection of MHC alleles. If one specific MHC molecule outperforms the others, this molecule is expected to become dominant in the population. For this reason, the large degree of observed polymorphism points to a frequency-dependent selection process of MHC molecules in populations. Since every agent has two sets of chromosomes, maximally two different MHC molecules at each MHC locus are present (one inherited from the mother and one from the father). Due

\footnotetext{
${ }^{12}$ For this reason it is common among anthropologists to use information about the frequency of different MHC molecules to trace ethnic origins of populations and to study the cultural mechanisms that can help explain why genes and culture may coincide [Durham 1992]. One allele typically dominates within a population, but rare variants are known to survive easily. The existence of a specific allele that is rare within one population but dominant in another reveals ethnic bonds between both populations in the past. Cavalli-Sforza et al. [1994] have contributed to the understanding of the ethnic origins of different groups and populations, also revealing similarities with the diffusion of linguistic elements over the world. Hewlett et al. [2002] have used genes and language as tools for interpreting the genetic diversity among a large number of African ethnic groups. We investigate the diversity of alleles per locus within a population, leaving aside possible ethnic traces revealed by specific or individual MHC alleles.
} 
to the high degree of MHC polymorphism in the population, there is a high probability of MHC heterozygosity (i.e., the presence of different alleles at the two chromosomes). Although the evolutionary advantage of MHC heterozygotes could explain the occurrence of polymorphism, a number of studies suggest a direct evolutionary advantage of rare alleles to be the main factor explaining the large degree of polymorphism of the MHC in populations. ${ }^{13}$ Such a direct advantage of rare alleles is present, because pathogens tend to adapt to the most common MHC molecules in the host population.

Several empirical studies suggest that MHC polymorphism also directly affects mating processes. ${ }^{14}$ Fish, mice and other animals turn out to prefer sexual partners with dissimilar MHC molecules. In addition, embryos with a large MHC similarity with their mother face a higher risk of preferential abortion. Experiments have shown that humans prefer the body odor of potential partners embodying a dissimilar MHC genotype, which increases the degree of polymorphism in a population. ${ }^{15}$ Both phenomena support the hypothesis that MHC diversity is important for evolutionary success.

Since class I MHC molecules are expressed by virtually all body cells, HLA alleles in humans can be traced by analysis of blood samples. There are two types of tests that are frequently used: serological tests, typing the specific HLA molecules expressed by a cell, and DNA tests, reading the structure of the genes that encode the HLA molecules. DNA typing is more expensive, but has the advantage that no fresh blood is needed, and that its resolution can be higher than that of serological tests. As a result of new DNA techniques the knowledge about subtle differences between HLA molecules is still increasing. At present there are still many questions regarding the specific role of HLA-A versus HLA-B. ${ }^{16}$

Originally, using serological tests, both HLA-A and HLA-B alleles have been classified according to a two-digit system, distinguishing 19 different HLA-A alleles varying from A01 to A43, and 42 HLA-B alleles, ranging from B07 to B78. More refined DNA methods enabled researchers to find differences within many two-digit groups. For that reason the classification has changed to a four-digit level. The first two digits indicate the old classification, while the last two digits include information about the particular subtype. At the same time, researchers recognized that many subtypes are actually almost functionally identical in the sense that they share similar peptide binding properties. Based on these binding properties Sette and Sidney [1999] and Lund et al. [2004] propose new

\footnotetext{
13 See e.g., De Boer et al. [2004] and Borghans et al. [2004] who argue that the MHC is polymorphic as a consequence of frequency dependent selection due to host-pathogen co-evolution, and not merely because of MHC heterozygote advantage. In addition, MHC polymorphism allows hosts to draw small and different samples from a pathogen's genome to induce an immune response.

${ }^{14}$ Penn [2002] provides an overview study addressing the relationship between sexual selection and MHC diversity.

${ }^{15}$ See e.g., Wedekind and Füri [1997] and Milinski and Wedekind [2001]. Reusch et al. [2001] provide interesting evidence on the stickleback mating behavior, which seems to be driven by odor as well.

${ }^{16}$ Kiepiela et al. [2004] provide evidence that HLA-B is dominant in the co-evolutionary process of the immune system and pathogens.
} 
groups of HLA "supertypes" of molecules that are functionally similar. For HLA-A these supertypes coincide to a large extent with the original two-digit grouping, but for HLA-B many molecules associated with different two-digit groups turn out to be functionally very similar. The knowledge about HLA-C is more limited, the available frequency tables contain many unknowns, and the number of populations for which HLA-C is available is relatively low. With respect to class II molecules, information for a representative sample of countries is currently not available.

\subsection{Data and Sample Construction}

Appendix A.I provides details about the data and its sources. Here we only discuss the most salient details. We have collected data from several sources about the frequency of HLA molecules in different populations. We have selected all known (two-digit) HLA-A and HLA-B alleles within many different populations.

Our primary data source has been the collection of HLA frequencies following the Eleventh International Histocompatibility Workshop and Conference. At this conference the results of identical HLA typing for a large number of ethnic groups were presented. In this way consistent information about allele frequencies within many populations could be identified. We use several secondary data sources to test the consistency of the data and to add a number of populations to our sample. For some populations HLA typing is obtained from regular tests because of tissue, organ or stem cell donations. ${ }^{17}$ To avoid selectivity and non-random sampling, only genetic information from healthy agents has been used, including only one observation when information of several siblings or parents within one family is present in the data.

The data on ethnic groups have been matched to countries to obtain information about macroeconomic indicators, such as GDP per capita. In some cases the link between ethnic groups and countries is not trivial. Whenever possible, we matched economic data of a country with information about HLA of the economic dominant ethnic group. Furthermore, for some ethnic groups no economic indicators were present, whereas for some countries no HLA information was available. Altogether, we obtained a sample of 63 countries.

\subsection{Frequency Dependence and Evolution of MHC Diversity}

MHC polymorphism points to a process of frequency-dependent selection with respect to these molecules. Interestingly, however, the observed frequency distribution of different

\footnotetext{
${ }^{17}$ Originally, the name $\mathrm{MHC}$ was given to a large genetic region containing genes that determine the success or failure of graft transplantation. If two agents share the same set of MHC molecules, transplantation has the largest chance of being successful. The larger the difference, the higher the probability of rejection of the transplant.
} 
molecules within a population does not appear to be a uniform distribution. Another observation is that the dominant allele differs between populations. ${ }^{18}$

Figure II shows the average frequency distribution of the 19 different HLA-A molecules and 42 HLA-B molecules in a population. Because different molecules are dominant in different populations, we rank-ordered the frequencies before taking averages over all populations. The graph in the first panel illustrates that in most populations there is one HLA-A molecule with a high frequency, of on average 26.9 percent. The average frequency of the second most-frequent molecule equals 17.0 percent. The relatively high presence of some molecules is more prominent for HLA-A than for HLA-B which is most likely due to the fact that there are 42 B-molecules compared to only 19 A-molecules, and because of the disagreement in the classification of HLA-B molecules, which only recently advanced to the formation of so-called supertypes (e.g., Lund et al. [2004]). The observed frequency-distributions of molecules suggest that, along with an individual selective pressure for a large variety of rare MHC alleles, there seems to be a selective pressure at work favoring the homogeneity of MHC alleles within populations.

As a measure of diversity we use $1-\sum_{k} F_{k}^{2}$ where $F_{k}$ is the frequency of type $k$ in the population. $F_{k}$ is known in genetics as the degree of heterozygosity (see Cavalli-Sforza et al. [1994]) and as the Herfindahl index in economics. ${ }^{19}$ The index equals $1-$ the probability that two persons in a population share the same molecule. ${ }^{20}$ When applied to small samples, a plain calculation of the sample diversity underestimates the diversity within the whole population. For that reason we corrected the estimator by subtracting the expected bias $\left(F_{k}\left(1-F_{k}\right) / n\right)$ from each component $F_{k}^{2}$. We present details about this approach in Appendix A.II. Simulation of the resulting measure of diversity suggests that for the smallest samples in our set $(n=100)$ the bias is reduced from approximately 0.010 (28.6 percent of a standard deviation) to 0.0005 (1.4 percent of one standard deviation) on a diversity scale ranging from 0.700 to 0.900 (with a standard deviation of 0.035 ).

Figure III shows how the frequency of the five most frequent HLA-A and HLA-B molecules is related to the measure of diversity. The horizontal axis is defined as the level of diversity within a population and the vertical axis shows the frequency of appearance of particular molecules. We observe a consistent relationship between the overall level of MHC diversity and the specific form of the distribution within populations. Especially the frequency of the most frequent MHC molecule is large when MHC diversity is low.

\footnotetext{
${ }^{18}$ The heterogeneity of $\mathrm{MHC}$ is unrelated to other aspects of human diversity. For example, Blood type O is known to be present in about 90 percent of the South-American population and traditionally the continental Western European populations are characterized by higher proportions of type A. The lowest frequency of O is found in Eastern Europe and Central Asia, where B is relatively common. There is no significant correlation between blood type dominance and MHC molecule dominance in our cross-section of populations. Also the degree of heterogeneity is unrelated.

${ }^{19}$ Our empirical results are robust to using different powers in this index.

${ }^{20}$ As a measure of polymorphism the "degree of heterozygosity" seems to be a misnomer. Based on Mendelian expectations, both measures of diversity will be identical however. Since there are reasons why the Mendelian rules do not hold for MHC (e.g., as a result of disassortative mating and preferential abortion), this measure reflects the degree of polymorphism rather than the degree of heterozygosity.
} 
The frequency of the second molecule also increases as MHC diversity decreases, but at a much lower pace. The frequency of the fifth molecule remains almost constant between a level of diversity of 0.754 (0.873) and 0.929 (0.959) for HLA-A (HLA-B) molecules but decreases when diversity falls below this level. Again the pattern is more pronounced for HLA-A molecules than it is for HLA-B molecules.

A link between the economic and biological domain only materializes if time horizons are comparable, which implies that economic circumstances have to remain stable for some time for an evolutionary equilibrium to emerge. Evolution of the diversity of MHC alleles in a population can be rapid for two reasons. First, there is a large evolutionary pressure on the MHC. Second, changes in diversity require only changes in MHC frequencies. A change in a distribution, such as presented in Figure II, only requires the characteristics of a fraction of the population to change. Importantly, the characteristics that need to increase in terms of frequency can already be present at high frequency in a population before the evolutionary change starts. We show below that a sufficient change in MHC diversity within a population can occur in four to ten generations. ${ }^{21}$

\subsection{Transmission of Pathogens and Immune Responses}

Infectious diseases spread in a number of ways between individual hosts. Most skin infections spread by direct skin contact (e.g., pox) or via the water (e.g., hookworm), while most respiratory infections spread by coughing and sneezing, and most intestinal infections by faeces and diarrhoea. Other pathogens spread as a result of sexual contacts (e.g., herpes, HIV and syphilis) and via blood or blood products (e.g., hepatitis B and $\mathrm{C}$ and malaria). Finally, insect and animal bites spread pathogens causing for example yellow fever, malaria and rabies.

Some pathogens spread more easily than others. ${ }^{22}$ In addition, when a pathogen spreads through a population, some hosts may contract the disease while others do not. These differences between hosts are largely caused by differences in HLA background. Some hosts manage to present a larger variety of pathogen peptides to their immune system than others, or happen to present peptides that the pathogen cannot mutate. Hosts may even get infected, transmit the virus, but fail to contract the disease because of immune control. Other infected hosts might contract the disease because of less effective immune responses. These cases can occur because time between infection and induction of an effective immune response can be used by a pathogen to infect other hosts.

\footnotetext{
${ }^{21}$ In contrast, for many other evolutionary changes a new and improved gene has to occur through mutation and suppress the previously dominant one, which (if successful at all) takes much longer. Aoki [1991] shows that lactose tolerance among Europeans increased from 5 to 70 percent in a period of about 5,000 years. Similarly, the establishment of the sickle cell gene that protects African farmers against malaria took around 10,000 years to materialize.

${ }^{22}$ In other words, the degree of contact between the host and the pathogen matters. This depends on the number of pathogens in the environment and the means by which they typically spread.
} 
Transmission of infectious diseases explains why agents with an adaptive immune system that differs from neighboring agents have a selective advantage. If this would be the only factor, the expected distribution of MHC molecules in populations would be uniform to ensure a maximum level of MHC diversity between hosts. The non-uniform shape of the frequency-dependent distribution of the MHC described above thus suggests that there are additional forces influencing MHC diversity within populations.

A prominent reason for the observed frequency distribution to be non-uniform is that properties of the immune system of one agent affect the health outcomes of other agents. If a host becomes infected but the adaptive immune system deals effectively with the infection, and thereby avoids infection of other individuals, this agent reduces the incidence of the disease in a population. In addition, the prevalence and reproduction rate of this infection in a particular environment will be lower if the proportion of agents with an adequate immune response in the population is higher. ${ }^{23}$ This is especially true for endemic diseases and for periodically returning (modified) pathogens with relatively high reproduction rates, such as the influenza virus.

One specific agent in a group can be infected by all others. The immune responses of all other individuals in the group therefore act as a protecting belt to any specific agent. If every agent has different MHC molecules, which are effective against different pathogens, every pathogen has ample opportunities to get through this protective belt, using the weakest link as host. For this specific agent it is optimal when the others share the same MHC molecules. Conditional on the MHC molecules of the other agents, however, it is advantageous to have a different MHC. When a new pathogen breaks through a protective wall, having a different MHC molecule provides the best opportunities for an effective immune response. The trade-off is that every agent who is better off in being different from the others is also part of the protecting belt of others, in which a lower level of MHC diversity is optimal. The optimal distribution of molecules for the group depends on the relative magnitude of both effects. A selfish agent will however only optimize its own benefits. Being similar is beneficial to the others, while being different is beneficial to any specific agent, so a prisoners dilemma occurs, which will lead to a higher level of MHC diversity than is optimal for the group as a whole.

In economic terms this means that there exists an externality in the immune responses of single agents to build resistance at the level of the population. As a result, there is no reason to assume an equilibrium in which a maximum level of MHC diversity is optimal. In case of a discrepancy between the individual equilibrium and the population's (social) optimum, any change in the degree to which agents internalize this externality affects the frequency distribution of MHC molecules in that population. For populations in which mutual dependence between agents in terms of production and economic outcomes is more

\footnotetext{
${ }^{23}$ The reproduction rate refers to the average number of susceptible agents infected by a single host; $R_{0}$ in epidemiology.
} 
important, the social optimum with lower levels of MHC diversity and a high prevalence of specific MHC types is more likely to be the observed immune system outcome, compared to populations in which mutual dependence is lower.

\section{Model}

\subsection{Modelling the MHC}

Consider a population with generations of $N_{g}$ agents. In each generation random and small groups of agents of size $n+1$ are formed. Every agent has $n$ randomly selected contemporary agents in close vicinity. These people are together because they cooperate in their work. This increases the probability of an agent to infect other members of the cooperative group. Further on we will also investigate the implications of their cooperative behavior for the immune system. Each period, agents have one unit of time available to work. After having contracted a disease a fraction $1-t_{i}$ is needed to recover, so a fraction $t_{i} \leq 1$ of this time can be used to produce. Let there be $m$ different MHC molecules (indexed $k$ or $l$ ) and $m$ types of pathogens (indexed $v$ or $w$ ). The immune responses induced by different MHC molecules differ in the capacity to prevent contraction and transmission of the disease. Each pathogen is assumed to have equal probability to be active in a certain (sub)period. Upon exposure to the pathogen, each of the $n$ agents have equal probability $(\alpha)$ of direct infection. When a person is infected, there is a probability $\bar{p}_{k v}$ of transmission to all the others in his group. This probability of transmission depends on the combination of the pathogen $(v)$, and the MHC molecules $(k)$ of the infected donor. Combined with the initial probability of infection $p_{k v}=\alpha \bar{p}_{k v}$ describes the probability that a host infects others. Once infected, a host contracts the disease with probability $q_{k v}$. We distinguish between $\bar{p}_{k v}$ and $q_{k v}$ because hosts may transmit an infection without contracting the disease, and vice versa, contract an infectious disease without transmitting it. There are two interesting specific cases. If $\bar{p}_{k v}=q_{k v}$ everyone who transmits contracts the disease and vice versa. If $q_{k v}=1$, everyone infected contracts the disease. In case an individual contracts a disease, production stops for a fixed period of time, until recovery.

For our purposes the most interesting case is when each MHC molecule confers an advantage to tackle a specific pathogen, while MHC molecules do not differ in their protective effect against other pathogens. The scheme below gives the values of $p_{k v}$ and $q_{k v}$ for this case. The schedule shows that MHC 1 is good for fighting disease 1 and so on. We use this scheme to illustrate the results of the model and refer to it as the symmetric case, i.e., the probability of transmission $p$ and contraction of disease $q$ are correlated. In addition, without loss of generality, we assume that $p_{\text {high }}>p_{\text {low }}$ and $q_{\text {high }}>q_{\text {low }}$. 


\begin{tabular}{|l|ccc|ccc|}
\hline & Transmission & & & Disease & & \\
& Disease 1 & Disease 2 & Disease 3 & Disease 1 & Disease 2 & Disease 3 \\
\hline \hline MHC 1 & $p_{11}=p_{\text {low }}$ & $p_{12}=p_{\text {high }}$ & $p_{13}=p_{\text {high }}$ & $q_{11}=q_{\text {low }}$ & $q_{12}=q_{\text {high }}$ & $q_{13}=q_{\text {high }}$ \\
MHC 2 & $p_{11}=p_{\text {high }}$ & $p_{22}=p_{\text {low }}$ & $p_{23}=p_{\text {high }}$ & $q_{21}=q_{\text {high }}$ & $q_{22}=q_{\text {low }}$ & $q_{23}=q_{\text {high }}$ \\
MHC 3 & $p_{11}=p_{\text {high }}$ & $p_{32}=p_{\text {high }}$ & $p_{33}=p_{\text {low }}$ & $q_{31}=q_{\text {high }}$ & $q_{32}=q_{\text {high }}$ & $q_{33}=q_{\text {low }}$ \\
\hline
\end{tabular}

The probability that an agent with MHC type $k$ contracts disease type $v$ depends on the probability of direct infection from outside the group $(\alpha)$ or infection through infection and transmission from at least one other agent in the group, multiplied by the probability of actually contracting the disease when infected, i.e.

$$
P(k, v)=\left(1-(1-\alpha) \prod_{l}\left(1-p_{l v}\right)^{n \pi_{l}}\right) q_{k v},
$$

where $\pi_{k}$ is the fraction in the population with MHC type $k$, with $\sum_{k} \pi_{k}=1$.

A social planner, who aims to minimize the number of infections in a population and who could set the distribution of MHC molecules in a population, would want to maximize income $Y$, which is equivalent to maximizing the time actually worked in a population. Hence, the social welfare function, $S$, equals

$$
\begin{gathered}
S=N_{g}\left(1-\sum_{v} \sum_{k} P(k, v)\right) \\
=N_{g}\left(1-\sum_{v}\left(\left(1-(1-\alpha) \prod_{l}\left(1-p_{l v}\right)^{n \pi_{l}}\right) \sum_{k}\left(\pi_{k} q_{k v}\right)\right)\right) .
\end{gathered}
$$

\subsection{The Evolutionary Equilibrium}

Assuming that the evolutionary success of $i\left(E S_{i}\right)$ depends positively on his economic performance (as lower output lowers the revenues and subsequently lowers the possibilities to use resources for reproduction and health), evolutionary success is negatively affected by the fraction of time the agent is recovering from a disease. More formally, evolutionary success of $i$ equals: $E S_{i}=f\left(1-t_{i}\right)$, with $f^{\prime}>0$. If $f$ can be approximated by a linear function, the expected value of the evolutionary pressure equals by approximation

$$
E\left(E S_{i}\right)=f\left(1-E\left(t_{i}\right)\right)
$$

An evolutionary stable equilibrium has to satisfy the equilibrium condition and the stability condition. ${ }^{24}$ The equilibrium condition implies that $E S_{i}=C(C>0)$ for all genetic characteristics of $i$ with a positive frequency in the population, while the stability condition implies that the evolutionary success of every characteristic with zero probability is less or equal to this level $\left(E S_{i} \leq C\right)$.

\footnotetext{
${ }^{24}$ See e.g., Maynard Smith and Price [1973] and Van Damme [1991] for definitions of these equilibria.
} 
Individual evolutionary selection increases the frequency of MHC molecules that lead to higher evolutionary success. This implies that in an evolutionary stable equilibrium either the evolutionary success of molecule $k$ equals the evolutionary success of molecule $\bar{k}$, or that the molecule with lower fate has frequency 0 .

For each combination of molecules $k$ and $\bar{k}$ with non-zero frequency, the equilibrium condition for mixed distributions equals

$$
\sum_{v}\left(1-(1-\alpha) \prod_{l}\left(1-p_{l v}\right)^{n \pi_{l}}\right) q_{k v}=\sum_{v}\left(1-(1-\alpha) \prod_{l}\left(1-p_{l v}\right)^{n \pi_{l}}\right) q_{\bar{k} v} .
$$

The expected number of agents who contract the disease upon exposure to virus $v$ if agent $i$ expresses $\mathrm{MHC}$ type $k$, equals

$$
\left(1-(1-\alpha)\left(1-p_{k v}\right)^{(n-1) \pi_{k}+1} \prod_{l \neq k}\left(1-p_{l v}\right)^{(n-1) \pi_{l}}\right) n \sum_{l} \pi_{l} q_{l v} .
$$

The condition for an evolutionary stable equilibrium, for each combination of $k$ and $\bar{k}$ with non-zero frequency, equals

$$
\begin{gathered}
\sum_{v}\left(1-(1-\alpha) \prod_{l}\left(1-p_{l v}\right)^{n \pi_{l}}\right) q_{k v}+ \\
\gamma\left(1-(1-\alpha)\left(1-p_{k v}\right)^{(n-1) \pi_{k}+1} \prod_{l \neq k}\left(1-p_{l v}\right)^{(n-1) \pi_{l}}\right) n \sum_{l} \pi_{l} q_{l v} \\
= \\
\sum_{v}\left(1-(1-\alpha) \prod_{l}\left(1-p_{l v}\right)^{n \pi_{l}}\right) q_{\bar{k} v}+ \\
\gamma\left(1-(1-\alpha)\left(1-p_{\bar{k} v}\right)^{(n-1) \pi_{\bar{k}}+1} \prod_{l \neq \bar{k}}\left(1-p_{l v}\right)^{(n-1) \pi_{l}}\right) n \sum_{l} \pi_{l} q_{l v} .
\end{gathered}
$$

In the symmetric case two results can be derived from the social welfare function (2) and the two conditions (4) and (5). We derive and proof these results in the theorems below.

Theorem 1 (Evolutionary Equilibrium without Cooperation): In the symmetric case when evolutionary selection depends only on individual health, and $p_{\text {high }} \neq p_{\text {low }}$ and $q_{\text {high }} \neq q_{\text {low }}$, the only evolutionary stable equilibrium equals $\pi_{k}=1 / m$ for every $k$

Proof: Using the symmetric parametrization equation (11) can be written as

$$
\begin{gathered}
\left(1-(1-\alpha)\left(1-p_{\text {low }}\right)^{n \pi_{k}}\left(1-p_{\text {high }}\right)^{n \pi_{\bar{k}}}\left(1-p_{\text {high }}\right)^{n\left(1-\pi_{k}-\pi_{\bar{k}}\right)}\right)\left(q_{\text {low }}-q_{\text {high }}\right)+ \\
\left(1-(1-\alpha)\left(1-p_{\text {high }}\right)^{n \pi_{k}}\left(1-p_{\text {low }}\right)^{n \pi_{\bar{k}}}\left(1-p_{\text {high }}\right)^{n\left(1-\pi_{k}-\pi_{\bar{k}}\right)}\right)\left(q_{\text {high }}-q_{\text {low }}\right)=0
\end{gathered}
$$

Because $q_{\text {high }} \neq q_{\text {low }}$ this can be rewritten as

$$
\left(\frac{1-p_{\text {low }}}{1-p_{\text {high }}}\right)^{n\left(\pi_{k}-\pi_{\bar{k}}\right)}=1
$$

Now $p_{\text {high }} \neq p_{\text {low }}$ yields $\pi_{k}=\pi_{\bar{k}}$, and thus $\pi_{k}=1 / m$. It is easily verified that the second order condition in this equilibrium holds. 
QED

Theorem 1 shows that when evolutionary success depends on individual health only, the distribution of MHC molecules in the population in an evolutionary stable equilibrium is always uniform and thus fully diverse. This observation, however, seems inconsistent with the observed distribution of MHC molecules in populations.

\section{Theorem 2 (Difference Between Social Optimum and Evolutionary Stable} Equilibrium without Cooperation): $\pi_{k}=1 / m$, for all $k$, is not a socially optimal distribution of MHC molecules, if $n \log \left(\frac{1-p_{\text {low }}}{1-p_{\text {high }}}\right)>2 \frac{q_{\text {high }}-q_{\text {low }}}{\frac{1}{m} q_{\text {high }}+\frac{m-1}{m} q_{\text {low }}}$.

Proof: Consider the situation in which the frequency of MHC molecule $k, \pi_{k}$, can be increased at the expense of molecule $\bar{k}$, with frequency $\pi_{\bar{k}}$, keeping the frequency of the other MHC molecules constant. Denoting $\bar{\pi}=\sum_{l \neq k, \bar{k}} \pi_{l}$, implies that $\pi_{\bar{k}}=\bar{\pi}-\pi_{k}$. The social welfare function (2) then reads

$$
\begin{gathered}
S=N_{g}-\left(1-(1-\alpha)\left(1-p_{\text {low }}\right)^{n \pi_{k}}\left(1-p_{\text {high }}\right)^{n\left(\bar{\pi}-\pi_{k}\right)} \prod_{l \neq k, \bar{k}}\left(1-p_{\text {low }}\right)^{n \pi_{l}}\right) \\
N_{g}\left(\pi_{k} q_{\text {low }}+\left(1-\pi_{k} q_{\text {high }}\right)\right) \\
-\left(1-(1-\alpha)\left(1-p_{\text {high }}\right)^{n \pi_{k}}\left(1-p_{\text {low }}\right)^{n\left(\bar{\pi}-\pi_{k}\right)} \prod_{l \neq k, \bar{k}}\left(1-p_{\text {low }}\right)^{n \pi_{l}}\right) \\
\left.N_{g}\left(\left(1-\bar{\pi}-\pi_{k}\right) q_{\text {low }}+\left(\bar{\pi}+\pi_{k}\right) q_{\text {high }}\right)\right) \\
-\sum_{v \neq k, \bar{k}}\left(1-(1-\alpha)\left(1-p_{\text {low }}\right)^{n(1-\bar{\pi})} \prod_{l \neq k, \bar{k}}\left(1-p_{\text {lv }}\right)^{n \pi_{l}}\right) N_{g}\left(\pi_{k} q_{\text {low }}+\left(1-\pi_{k} q_{\text {high }}\right)\right) .
\end{gathered}
$$

It is easily verified that the derivative with respect to $\pi_{k}$ of this function, if $\pi_{l}=1 / \mathrm{m}$ for all $l$, equals 0 . Therefore, the social welfare function always has an optimum in the distribution $(1 / m, 1 / m, \ldots, 1 / m)$ of MHC molecules in the symmetric case.

This optimum is not a maximum if the second derivative of the welfare function is positive in $(1 / m, 1 / m, \ldots, 1 / m)$. The second derivative in this point equals:

$$
\begin{gathered}
\left.\frac{d^{2} S}{d \pi_{k}^{2}}\right|_{(1 / m, 1 / m, \ldots, 1 / m)}=2 m\left(q_{\text {low }}-q_{\text {high }}\right)- \\
n\left(q_{\text {low }}+(m-1) q_{\text {high }}\right) \log \left(1-p_{\text {high }}\right)+n\left(q_{\text {low }}+(m-1) q_{\text {high }}\right) \log \left(1-p_{\text {low }}\right)
\end{gathered}
$$

This expression is positive if

$$
n \log \left(\frac{1-p_{\text {low }}}{1-p_{\text {high }}}\right)>2 \frac{q_{\text {high }}-q_{\text {low }}}{\frac{1}{m} q_{\text {high }}+\frac{m-1}{m} q_{\text {low }}} .
$$

QED

Theorem 2 shows that for certain parameter values of the model the social optimum is equal to the evolutionary stable equilibrium, but for other parameters the social optimum is a different one. In the latter case there is a discrepancy between the outcome of the 
individual evolutionary selection process and the social optimum. This implies that MHC diversity in the social optimum is lower than in the evolutionary stable equilibrium. This discrepancy will occur when $n$ is sufficiently large, $p_{\text {high }}-p_{\text {low }}$ is sufficiently large, or $q_{\text {high }}-q_{\text {low }}$ is sufficiently low. Increasing $m$ also shifts the balance in the advantage of a discrepancy between the social optimum and the individual equilibrium.

\subsection{Cooperation}

The question is how the selfish evolutionary equilibrium will change once people become mutually dependent because of cooperation. Following the structure of a linear public goods game, each agent can decide to spend a fraction of time $\left(\bar{\gamma}_{i}\right)$ to a joint project and $\left(1-\bar{\gamma}_{i}\right)$ to solo activities. Remember that agents are part of a small group of $n+1$ agents in which infectious diseases easily spread. Total output of a cooperative project equals $Q \sum_{j} \bar{\gamma}_{j} t_{j}$, where $Q$ is the return to the public good investments. Output will be shared among the agents, so every agent receives $\frac{Q}{n+1} \sum_{j} \bar{\gamma}_{j} t_{j}$. The marginal per capita return equals $\frac{Q}{n+1}$. The output of a solo project equals $\left(1-\bar{\gamma}_{i}\right) t_{i}$.

If $Q<1$ cooperation is not beneficial and if $Q>n+1$, agents voluntarily cooperate completely (in a Nash equilibrium): $\bar{\gamma}_{i}=t_{i}$. The interesting case is $1<Q<n+1$, where the Nash equilibrium induces solo activities only $\left(\bar{\gamma}_{i}=0\right)$, since $\frac{\mathrm{d}\left(1-\bar{\gamma}_{i}\right)}{\mathrm{d} \bar{\gamma}_{i}}>\frac{\mathrm{d} Q \bar{\gamma}_{i} / n+1}{\mathrm{~d} \bar{\gamma}_{i}}$. In cases where individual optimization does not lead to social optimality, rules, altruism, social pressure or reciprocal punishment can lead to higher levels of cooperation.

We assume that groups of agents expect a target level of cooperation $\bar{\gamma}$. Agents who put less effort in this joint project are punished, while those who invest more are rewarded. The punishment function is defined as $\rho t_{i}\left(e^{\frac{\bar{\gamma}-\gamma_{i}}{\bar{\gamma}}}-1\right)$, with $\rho \geq 0$. Now, the income of agent $i$ equals

$$
Y_{i}=\left(1-\bar{\gamma}_{i}\right) t_{i}+\sum_{j} \frac{Q}{n+1} \bar{\gamma}_{j} t_{j}-\rho t_{i}\left(e^{\frac{\bar{\gamma}-\bar{\gamma}_{i}}{\bar{\gamma}}}-1\right)
$$

where the first term on the left-hand side is solo production, the second term joint production and the final term punishment. The optimal value of $\bar{\gamma}_{i}$ can be derived from the first order condition and equals

$$
\frac{d Y_{i}}{d \bar{\gamma}_{i}}=t_{i}\left(-1+\frac{Q}{n+1}+\frac{\rho}{\bar{\gamma}} t_{i}\left(e^{\frac{\bar{\gamma}-\bar{\gamma}_{i}}{\bar{\gamma}}}-1\right)\right),
$$

which implies that

$$
\frac{\bar{\gamma}-\bar{\gamma}_{i}}{\bar{\gamma}}=\ln \left(\frac{\frac{n+1-Q}{n+1} \bar{\gamma}}{\rho}\right) .
$$

So every target level of cooperation $(\bar{\gamma})$ is related to actual cooperative behavior $\left(\bar{\gamma}_{i}\right)$. We impose that in every population a long-run equilibrium of the social norm will be settled 
in which the target value of cooperation is equal to the actual degree of cooperation. Then, the socially expected behavior equals the usual behavior of the agents, i.e.,

$$
\bar{\gamma}=\rho \frac{n+1}{n+1-Q}
$$

which reveals that $\bar{\gamma}$ is increasing with the level of punishment and with $Q$, and decreasing with the size of the group $n+1$. Agent $i$ 's income in this equilibrium then equals

$$
Y_{i}=\left(\frac{(n+1)(1-\bar{\gamma})+Q \bar{\gamma}}{n+1}\right) t_{i}+\sum_{j \neq i}\left(\frac{1}{n+1} Q \bar{\gamma}\right) t_{j}
$$

which exists of an individual and a group component (of course agent $i$ contributes to the group income too). Using the symmetry of the model it can be derived that the expected income per worker equals

$$
E\left(Y_{i}\right)=((1-\bar{\gamma})+Q \bar{\gamma}) E\left(t_{i}\right)
$$

which shows that income rises from $t_{i}$ to $Q t_{i}$ when $\bar{\gamma}$ shifts from 0 to 1 . If the variation between countries in terms of $E\left(t_{i}\right)$ is smaller relative to the variation in $Q$, differences in cooperation between individuals are the main determinant of income.

Crucial for the model, however, is that differences in the degree of cooperation change evolutionary pressure regarding the immune system. Defining

$$
\gamma=\frac{Q \bar{\gamma}}{\frac{(n+1)(1-\bar{\gamma})+Q \bar{\gamma}}{n+1}}
$$

to normalize agent $i$ 's own contribution to one the participation by other agents contributes with weight $\gamma$ to the performance of $i$. Consequently, the overall income of $i$ depends more on the health status of others, when cooperation $\bar{\gamma}$ increases. This result shows that cooperation leads to mutual dependence among agents cooperating in small groups.

Extending now the definition of evolutionary success of $i\left(E S_{i}\right)$ also incorporating the influence on economic performance of $i$ through the productivity of others, i.e. the time the other agents are recovering, gives: $E S_{i}=f\left(1-t_{i}+\gamma \sum_{j \neq i} 1-t_{j}\right)$, with $f^{\prime}>0$. If $f$ can again be approximated by a linear function, the expected value of the evolutionary pressure equals by approximation

$$
E\left(E S_{i}\right)=f\left(1-E\left(t_{i}\right)+\gamma n\left(1-E\left(t_{j}\right)\right)\right.
$$

Theorem 3 (Evolutionary Stable Equilibrium with Cooperation): If evolutionary selection depends on individual and co-worker health (i.e., $\gamma>0$ ), there is a value of $\gamma$ for which the evolutionary stable equilibrium equals the social optimum. If $p_{\text {high }}$ and $p_{\text {low }}$ are small, the value of $\gamma$ for which this equality holds, is close to unity. 
Proof: We need to show that for a certain value of $\gamma$ the condition for an evolutionary stable equilibrium equals the first-order condition for a social optimum. Again, as in (9), consider the situation in which in the social welfare function the frequency of $k$ is changed at the cost of $\bar{k}$. The condition for an Evolutionary Stable Equilibrium equals:

$$
\begin{aligned}
& \left(1-(1-\alpha)\left(1-p_{k k}\right)^{n \pi_{k}}\left(1-p_{\bar{k} k}\right)^{n \pi_{\bar{k}}} \prod_{l \neq k, \bar{k}}\left(1-p_{l k}\right)^{n \pi_{l}}\right)\left(q_{k k}-q_{\bar{k} k}\right) \\
& +\left(1-(1-\alpha)\left(1-p_{k \bar{k}}\right)^{n \pi_{k}}\left(1-p_{\bar{k} \bar{k}}\right)^{n \pi_{\bar{k}}} \prod_{l \neq k, \bar{k}}\left(1-p_{l \bar{k}}\right)^{n \pi_{l}}\right)\left(q_{k \bar{k}}-q_{\bar{k} \bar{k}}\right) \\
& +\gamma\left(p_{k k}-p_{\bar{k} k}\right) \\
& \left(1-(1-\alpha)\left(1-p_{k k}\right)^{(n-1) \pi_{k}}\left(1-p_{\bar{k} k}\right)^{(n-1) \pi_{\bar{k}}} \prod_{l \neq k, \bar{k}}\left(1-p_{l k}\right)^{(n-1) \pi_{l}}\right) n \sum_{l} \pi_{l} q_{l k} \\
& +\gamma\left(p_{k \bar{k}}-p_{\bar{k} \bar{k}}\right) \\
& \left(1-(1-\alpha)\left(1-p_{k \bar{k}}\right)^{(n-1) \pi_{k}}\left(1-p_{\bar{k} \bar{k}}\right)^{(n-1) \pi_{\bar{k}}} \prod_{l \neq k, \bar{k}}\left(1-p_{l \bar{k}}\right)^{(n-1) \pi_{l}}\right) n \sum_{l} \pi_{l} q_{l \bar{k}}=0 .
\end{aligned}
$$

The first-order condition for a social optimum equals:

$$
\begin{aligned}
& \left(1-(1-\alpha)\left(1-p_{k k}\right)^{n \pi_{k}}\left(1-p_{\bar{k} k}\right)^{n \pi_{\bar{k}}} \prod_{l \neq k, \bar{k}}\left(1-p_{l k}\right)^{n \pi_{l}}\right)\left(q_{k k}-q_{\bar{k} k}\right) \\
& +\left(1-(1-\alpha)\left(1-p_{k \bar{k}}\right)^{n \pi_{k}}\left(1-p_{\bar{k} \bar{k}}\right)^{n \pi_{\bar{k}}} \prod_{l \neq k, \bar{k}}\left(1-p_{l \bar{k}}\right)^{n \pi_{l}}\right)\left(q_{k \bar{k}}-q_{\bar{k} \bar{k}}\right) \\
& +\gamma\left(\log \left(1-p_{k k}\right)-\log \left(1-p_{\bar{k} k}\right)\right) \\
& \left(1-(1-\alpha)\left(1-p_{k k}\right)^{(n-1) \pi_{k}}\left(1-p_{\bar{k} k}\right)^{(n-1) \pi_{\bar{k}}} \prod_{l \neq k, \bar{k}}\left(1-p_{l k}\right)^{(n-1) \pi_{l}}\right) n \sum_{l} \pi_{l} q_{l k} \\
& +\gamma\left(\log \left(1-p_{k \bar{k}}\right)-\log \left(1-p_{\bar{k} \bar{k}}\right)\right) \\
& \left(1-(1-\alpha)\left(1-p_{k \bar{k}}\right)^{(n-1) \pi_{k}}\left(1-p_{\bar{k} \bar{k}}\right)^{(n-1) \pi_{\bar{k}}} \prod_{l \neq k, \bar{k}}\left(1-p_{l \bar{k}}\right)^{(n-1) \pi_{l}}\right) n \sum_{l} \pi_{l} q_{l \bar{k}}=0 .
\end{aligned}
$$

In the symmetric case these conditions are equal if

$$
\gamma=\frac{\left(1-p_{\text {low }}\right)^{\pi_{A} k}\left(1-p_{\text {high }}\right)^{\pi_{\bar{k}}}}{p_{\text {high }}-p_{\text {low }}}\left(\log \left(1-p_{\text {high }}\right)-\log \left(1-p_{\text {low }}\right)\right) .
$$

Suppose now that $p_{\text {low }}=\lambda p_{\text {high }}$. Then

$$
\lim _{p_{\text {high }} \rightarrow 0} \frac{\left(1-p_{\text {low }}\right)^{\pi_{k}}\left(1-p_{\text {high }}\right)^{\pi_{\bar{k}}}}{p_{\text {high }}-p_{\text {low }}}\left(\log \left(1-p_{\text {high }}\right)-\log \left(1-p_{\text {low }}\right)\right)=1 .
$$

QED

The core message of Theorems (1-3) is that if the social optimum differs from the frequency distribution of $\mathrm{MHC}$ molecules that results from individual selection, the evolutionary stable equilibrium gets closer to the social optimum when $\gamma$ - the degree to which evolutionary success of one agent depends on the health of the other $n$ agents increases. Figure IVa provides the frequency distribution in an evolutionary stable equilibrium for different values of $\gamma$ when $m=2$. When $\gamma=0$ the distribution is $1 / 2,1 / 2$. When $\gamma$ rises, the distribution changes gradually to 0,1 (or 1,0), i.e., the social optimum.

Figure IVb illustrates the results for the model with three types of MHC molecules. The simulation results replicate the typical patterns in the frequency distribution of HLAA and HLA-B shown in Figure II in Section 2. In equilibrium the frequencies of MHC 
molecules is not uniform, but each molecule has a different frequency. Furthermore, with decreasing levels of diversity (i.e., when $\gamma \rightarrow 1$ ) one allele becomes more dominant and the frequency of others decreases, a feature observed in the distribution of HLA molecules.

Taken together, the model shows that under certain circumstances the health status of a population is better off with low levels of MHC diversity, whereas individual selection processes tend to increase diversity. In more cooperative populations, evolutionary pressure shifts the immune system from the selfish one with high levels of diversity to the more efficient social optimum with lower levels of MHC diversity. Consequently, the level of MHC diversity mirrors a population's level of cooperative behavior. This finding explains the typical non-uniform pattern in HLA-A and HLA-B frequencies observed in Figures II and III. Moreover, the model puts forward three other predictions. First, if there is indeed a discrepancy between the social optimum and the selfish equilibrium, low levels of MHC diversity in a population should be associated with better health outcomes. Second, if such differences between countries reflect differences in the way people cooperate, MHC diversity should be negatively related to indicators of cooperative behavior. Finally, this mechanism only works if cooperative behavior has a higher output relative to carrying out solo projects. Hence, economic performance should correlate negatively with MHC diversity.

\subsection{The Pace of Change of the Evolutionary Process}

A crucial requirement for a satisfactory explanation of a relationship between economic outcomes and genetic evolution is a short time scale of the evolutionary adjustment. To analyze the pace of adjustment we simulate the model for a certain value of $\gamma$ until the frequency distribution converges, and then change $\gamma$. Table I shows what happens in a case with four different MHC molecules, for which we increase the value of $\gamma$ such that the equilibrium diversity shifts from 0.700 to 0.600 . Column (1) and (2) illustrate the equilibrium frequency distributions for both situations. In an equilibrium every $\mathrm{MHC}$ molecule has the same fitness, i.e. two agents with different MHC molecules must have the same expected number of children. When changing $\gamma$ when the system is in equilibrium, the fitness of each molecule changes. Column (4) provides the fitness of each MHC molecule immediately after the shift in $\gamma$. Since $\gamma$ increases, the fitness of relatively frequent (rare) molecules increases (decreases). At present there is no evidence about the actual size of fitness differentials and we calibrated the simulation to obtain a 1.050 fitness parameter for the most successful allele. This seems a conservative estimate since it implies that people with molecule MHC-1 have a five percent higher effective fertility rate than the average level of reproduction in this population. This is a very small difference in terms of actual offspring, which would most likely not be observed in reality for a 
reasonably long period of time. Under these assumptions it takes seven generations to bridge the half-life of the difference in diversity between the old and new situation. If people get offspring at the age of 20, this equals a time-span of 140 years.

The numbers in Table I illustrate why the pace of this evolutionary change is relatively high. In Column (3) we provide information about the frequency differences between both equilibria. Adding all increases or all decreases shows that only 17.62 percent of the population has to "change genes" to obtain the new equilibrium. Furthermore, the genes that need to increase in frequency are already present in the population and need not be developed. An increase of five percent in population size, increases the fraction of the population expressing molecule MHC-1 with $0.050 * 35.980=1.799$ percentage points in the next generation.

To address the robustness of this process we carried out several simulations, including different parameter values. Generally, we find that four to ten generations suffice to reduce half of the gap between the actual MHC diversity in the population and the evolutionary stable equilibrium. This makes us confident that our measure of human evolution is able to change with changes in economic circumstances.

\section{Empirical Results}

\subsection{Cooperative Behavior and the MHC}

Cooperative behavior leads to higher levels of mutual dependence, which results in agents being more dependent on the health of agents they cooperate with. Consequently, the health of others will be "internalized" in the evolution of the individual agent's immune system and MHC diversity will be lower in an evolutionary stable equilibrium. To establish a correlation between levels of cooperative behavior and MHC diversity, we collected information from a number of experimental studies on offer rates in ultimatum games and the amounts of money sent in trust games, see Appendix A.IV. ${ }^{25}$ Most studies include various forms of games, but also report results from a "standard" experiment. These are the data we are interested in for the collection of information across countries. Offer rates in ultimatum games and the money sent in trust games incorporate the agents' view on fairness and trust, which are crucial ingredients in shaping cooperation (e.g., Fehr and Schmidt [1999]), so we expect a negative correlation between these experimental variables and MHC diversity.

A main finding in ultimatum games is that proposers offer more than backward induction implies. This behavior is interpreted as a taste for fairness and the anticipation

\footnotetext{
${ }^{25}$ To collect these studies we have benefitted from the web pages of Alvin Roth and Charles Holt as well as from the meta-analysis carried out by Oosterbeek et al. [2004] in case of ultimatum games.
} 
that low offers are likely to be rejected. We restrict our sample to offer rates of standard ultimatum games, which come in two forms. The most common form is that a player offers the division of an amount of money to another player, which is either accepted or rejected. If accepted the money will be split, if not both players receive nothing. The other form is one in which the responder has to clarify beforehand which split will be acceptable. ${ }^{26}$ We include a dummy variable in the regression analysis to control for these two types of set ups. Another difference when comparing games is the variety of stakes. We only use studies in which real money is at stake and include the stake in US dollars relative to GDP per capita in the regression equation. ${ }^{27}$ Next, there is an issue of learning in repeating experiments. That is why we only use the offer rates from the first round in case of multiple rounds and add a dummy variable to make sure these experiments are not different in other dimensions. ${ }^{28}$ Finally, it is debated whether it matters if ultimatum games are played by students or not. To deal with this issue we include a dummy variable for students in the regression equation. The number of countries for which MHC diversity and ultimatum game offer rates are available equals 23; see Table A.II in the Appendix for a listing of these studies.

In trust games an investor and a trustee receive an initial amount of money. The investor can transfer between zero and one hundred percent of this money to the trustee, money which is tripled by the experimenter. After the trustee has been informed about the transfer, the trustee has the option of sending any amount between zero and the total sum of money available back to the investor. The investor's outcome equals the initial endowment, minus the investment, plus the back transfer from the trustee. The trustee's payoff equals the initial endowment, plus the tripled transfer from the investor, minus the back transfer to the investor. The trust between the investor and trustee is usually measured by the amount of money sent from the investor to the trustee because the investor faces a dilemma. If he correctly trusts the investor he increases his payoff, but if his trust is abused he is worse off. Generally, investors are shown to be averse to such risks. ${ }^{29}$ In addition, there are likely to be differences in the outcomes of trust games across social groups and populations. ${ }^{30}$ We have been able to collect information from 21 countries; see Table A.III in the Appendix for a listing of these studies. The amount of money sent has been recoded into shares, with higher shares indicating higher amounts of money that have been sent from the investor to the trustee. The mean (standard

\footnotetext{
${ }^{26}$ This latter type of game is typically used to collect a player's complete strategy instead of a conditional strategy. Güth and Tietz [1990] argue that both games are likely to yield different offer rates because the game in which players have to reveal their strategy is likely to strengthen fairness.

${ }^{27}$ Slomin and Roth [1998] find that differences in stakes only affect the rejection rate, not the offer rate. Higher stakes yield lower rejection rates. Nevertheless, we take stakes into account to make sure our results are not influenced by differences in stakes.

${ }^{28}$ Roth and Erev [1995] show that the offer rates go down when the proposer gains experience.

${ }^{29}$ See e.g., Fehr and Schmidt [1999] and Holt and Laury [2002].

${ }^{30}$ See e.g., Berg et al. [1995], Bohnet and Zeckhauser [2004] and Hong and Bohnet [2004].
} 
deviation) share equals 54.224 (11.660), which implies that investors sent about 55 percent of their endowment to the trustee. In two of the trust games the money that was sent was doubled, instead of tripled. We include a dummy variable to control for this distinction between games. In nine games only the investor has been given an initial endowment. Again we include a dummy variable to control for this feature. Finally, we also include the stakes and a dummy for whether the subjects are students.

Panels $\mathrm{A}$ and $\mathrm{B}$ in Figure $\mathrm{V}$ present the correlation between HLA-A and HLA-B diversity and the offer rates in ultimatum games in 23 countries. The relationship indicates a negative correlation, which is confirmed by the estimates presented in columns (1) and (3) of Table II. Panels C and D present the same correlations for the amount of money sent in trust games and MHC diversity. The estimates in columns (6) and (8) of Table II show that the correlation is also negative but less strong for HLA-B diversity in our sample of 21 countries. In the other columns of Table II we add the above mentioned control variables to the regression analysis, but the conclusions remain similar. The measure of MHC diversity includes most likely some measurement error, which could bias its estimates towards zero. To deal with measurement error in MHC diversity we instrument HLA-A diversity with HLA-B diversity (the correlation coefficient between HLA-A and HLA-B diversity is significant and equals 0.508 ). The estimates are presented in columns (5) and (10) in Table II. The correlation between the offer rate and HLA-A diversity becomes stronger, but the correlation with the amount of money sent in trust games does not improve.

Overall these correlations suggest that populations offering higher rates in ultimatum games and sending higher amounts of money in trust games are characterized by lower levels of MHC diversity. These results confirm that measures of cooperative behavior in a population, based on experimental approaches, are correlated with MHC diversity.

\subsection{Health Outcomes}

A second implication of our model is that a discrepancy between the individual stable evolutionary equilibrium and the social optimum, should be associated with a correlation between MHC diversity and health outcomes. Regarding the central role of class I MHC molecules in the control of viral infections, there should especially be a lower incidence of viral infections in populations with low MHC diversity. To assess the relationship between health outcomes and MHC diversity we use information about life expectancy to evaluate the effect of MHC diversity on health outcomes in general. The number of deaths caused by viral infections as a fraction of the total population is used as a more detailed proxy for health outcomes. Life expectancy at birth is taken from the 2002 World 
Development Indicators, and refers to the situation in $1990 .^{31}$ Information on mortality as a result of viral infections is taken from the 2000 Mortality Database of the World Health Organization.

Figure VI presents the relationship between health outcomes and MHC diversity by showing a negative and statistically significant correlation between life expectancy at birth in 1990 and HLA-A and HLA-B diversity for the sample of 63 countries. The horizontal axis measures HLA-A diversity and the vertical axis life expectancy at birth in 1990 . The correlation between HLA-A (HLA-B) diversity and life expectancy at birth is -0.265 $(-0.228)$ and significant at the five percent level. The bottom panel presents a positive correlation between viral infections and HLA-A and HLA-B diversity for a sub-sample of 47 countries for which information on viral infections is available. The correlation between HLA-A (HLA-B) diversity and viral infections is 0.445 (0.403) and significant at the five percent level.

Since lower MHC diversity mirrors mutual dependence and will be associated with higher levels of economic performance, this correlation is likely to include both the direct effect of a better immune response and the indirect effect of MHC diversity on life expectancy working through income. Effective treatment and preventive measures are likely to increase life expectancy. Furthermore, a more advanced health system could change the observed level of MHC diversity because the threat of pathogens will diminish. We control for differences in health systems and include the log of health expenditures per capita in constant 1990 US\$ in 1995. In addition, we average two measures of child immunization to capture vaccination coverage of children under one year of age: (i) child immunization against diphtheria, pertussis (or whooping cough), and tetanus (DPT) after receiving three doses of vaccine; and (ii) child immunization against measles after receiving one dose of vaccine. Pathogen pressure is known to be different in various parts of the world, and to be relatively high close to the equator because the incidence of infections as well as outbreaks of new infections in single areas is higher. Since a higher level of pathogen pressure in an environment will lead to more diseases, it could induce a higher equilibrium level of MHC diversity in a population. Since such a relationship between pathogen pressure and MHC diversity could bias our estimates we use several proxies as a control for pathogen pressure. From Hall and Jones [1999] we use absolute latitude to capture the effect of populations residing close to the equator having a higher prevalence and incidence of infectious diseases. From Gallup et al. [2001] we add the following information into one variable: (i) the fraction of tropical area of a country, (ii) the fraction of the population living in tropical areas, and (iii) the tropical climate zone which is an indicator measuring the extent to which a country is regarded tropical. The variable used

\footnotetext{
${ }^{31}$ For 1990 the number of populations for which life expectancy is available is the largest. Using life expectancy at birth in 1995 or 2000 yields similar estimates but lacks information about a number of developing countries.
} 
in the regression equation measures the standardized averages of the three indicators.

Table III provides the main results for using life expectancy at birth as the dependent variable. Column (1) shows the OLS relationship between HLA-A diversity and life expectancy at birth in 1990 by estimating the following model:

$$
L E_{c_{1990}}=C+\alpha_{1} M H C_{c}+\alpha_{2} P P_{c}+\alpha_{3} L A_{c}+\alpha_{4} H E_{c}+\alpha_{5} I M M_{c}+\alpha_{6} O E C D_{c}+\epsilon_{c},
$$

where $L E_{c_{1990}}$ is life expectancy at birth in country $c$ in 1990 . The main variable of interest is $M H C_{c}$, the level of HLA-A or HLA-B diversity in country $c ; \epsilon_{c}$ is an error term with the usual properties, capturing all omitted factors. $P P_{c}$ measures the degree of tropical features in country $c$ and $L A_{c}$ is absolute latitude, which together should capture the effect of different circumstances with regard to pathogen pressure. $H E_{c}$ is the $\log$ of health expenditures per capita in 1995 and $I M M_{c}$ is country $c$ 's average immunization rate against DPT and measles, which together form the set of variables capturing possible differences in the country's level of health advancement.

Column (1) shows a statistically significant correlation between the level of HLA-A diversity and life expectancy at birth. The estimate suggests that a one-standard deviation (i.e., 0.035) increase in MHC diversity reduces equilibrium life expectancy by 0.184 years, which yields a reduction of life expectancy at birth of 0.521 years when MHC diversity is increased by 10 percentage points. These seem to be estimates of reasonable magnitude relative to the mean (standard deviation) of life expectancy at birth in 1990 in the sample, which is 69.201 (7.691) years. Column (2) presents comparable results when using HLA-B diversity.

Next, we add the log of GDP per capita in 1960 to the equation $\left(G D P_{c_{1960}}\right)$. The argument for including this covariate is that higher levels of income might have a direct effect on life expectancy at birth because people are able to acquire, for example, better food and housing. The estimates for $\alpha_{1}$ reported in columns (3) and (4) do not look different from the previous ones. Actually, the estimates on $\alpha_{1}$ are even slightly higher. The coefficient on GDP per capita in 1960 is statistically significant, which suggests some direct causal effect of income on life expectancy. ${ }^{32}$ The estimates suggest that the effects of income on life expectancy go through more economic fortunes and higher levels of mutual dependence, captured by MHC diversity.

The 2SLS estimates, using HLA-B diversity as an instrument for HLA-A diversity, are reported in Columns (5) and (6) of Table III. The estimates suggest that taking care of the measurement error increases the estimated coefficients for $\alpha_{1}$ considerably. The coefficients suggest that a one-standard deviation increase in MHC diversity reduces life expectancy at birth by 0.205 and 0.438 years, respectively. We have experimented with a

\footnotetext{
${ }^{32}$ Note that Cuba does not report information on income variables, so the sample is reduced to 62 countries.
} 
host of different specifications and included different regional indicators into the regression equations, but the results remain similar.

Because of the specific role of MHC type I molecules, our model predicts that MHC diversity is especially related to differences in health status related to viral infections. ${ }^{33}$ Table IV provides the main results for using $V I_{c}$, the fraction of the population that has died from viral infections (multiplied by 1,000), as the dependent variable. Column (1) and (2) show the OLS relationship between MHC diversity and viral infections by estimating the same models as for life expectancy. The estimate for $\alpha_{1}$ recovers the positive relationship between HLA-A (HLA-B) diversity and the fraction of the population that has died from viral infections and suggests that a one-standard deviation increase in HLA-A (HLA-B) diversity increases mortality by 4.93 (4.44) percent. Columns (3) and (4) reports the estimates for $\alpha_{1}$ by adding $G D P_{c_{1960}}$. Finally, the 2SLS estimates in columns (5) and (6) suggest a robust positive correlation between MHC diversity and viral infections.

These estimates suggest that higher levels of MHC class I diversity are correlated with lower life expectancy and a higher incidence of people dying from viral infections. Our proxies for health outcomes are related to mortality, while in the model the fact that diseases prevent agents from working, already generates the results. Ideally we would want to measure the average days of absence from work due to diseases for our sample of countries, but such data are not available for a large set of countries. Finally, from the perspective of our theory, the estimates imply that there is a discrepancy between the individual evolutionary equilibrium and the social optimum. These conclusions remain when we control for observed differences in pathogen pressure and differences in advancement of health systems and economic fortunes between the populations in the sample.

\subsection{Economic Performance}

A final empirical relationship we want to establish is one between economic outcomes and MHC diversity. Ultimately, the basic idea of the public goods game is that it increases output and mutual dependence. As a consequence, societies that are better able to cope with public good dilemmas by means of altruism, social norms or punishment, will be

\footnotetext{
${ }^{33}$ The data are taken from the 2000 WHO Mortality Database or the most recent year if 2000 is unavailable. The Appendix provides more details about the definition of infectious diseases from this data source. Gallup et al. [2001] provide information for the incidence of single (infectious) diseases. We do not use this information since we would aim to capture the effects of overall pathogen pressure and not the incidence of individual diseases. Information about infectious diseases is available for 47 populations only. We do not have information for the following countries: Botswana, Cape Verde, China, the Democratic Republic of Congo, India, Indonesia, Kenya, the Federal Republic of Macedonia, Morocco, Oman, Pakistan, Senegal, Turkey, Uganda, Vietnam, and Zambia. We do not include HIV infections because a number of countries have extreme high AIDS death rates while other countries do not report these numbers for political and socioeconomic reasons. In addition, differences in the availability of medication and ways which governments deal with the HIV epidemic capture effects we do not want to take into account in the empirical analysis.
} 
more successful in economic terms and at the same time produce a higher degree of mutual dependence. This level of mutual dependency is mirrored by the level of MHC diversity in a population. Figure VII shows a significant negative correlation between HLA-A and HLA-B diversity and per capital economic growth in the period 1960-2000 of -0.437 and -0.321 , respectively.

Column (1) in the first panel of Table V reports OLS estimates of the following model:

$$
\Delta G D P_{c_{1960-2000}}=C+\alpha_{1} G D P_{c_{1960}}+\alpha_{2} H L A-A_{c}+\alpha_{3} O E C D_{c}+\epsilon_{c}
$$

where $\Delta G D P_{c_{1960-2000}}$ is defined as the log difference between GDP per capita in 2000 and 1960 , and $G D P_{c_{1960}}$ as the log of GDP per capita in 1960. The coefficient of interest is the one on $\alpha_{2}$. The estimate of $\alpha_{2}$ illustrates a strong and negative correlation between HLA-A diversity and economic growth over this forty year period, which is significant at the one percent level. Estimates for HLA-B diversity show similar results for all estimates shown in this section but are suppressed to preserve space. In subsequent columns we replace $\Delta G D P_{c_{1960-2000}}$ by more recent changes in GDP per capita. Column (2) reports the estimates for the period 1970-2000 and Column (3) for the period 1980-2000. Finally, Columns (4)-(6) present the 2SLS estimates, where we use HLA-B as an instrument for HLA-A diversity. All estimates are statistically significant.

There might be some concern about regional correlation, since the Asian countries seem to have grown fast and reveal a relatively low level of HLA-A diversity. In addition, the African countries are generally poor and have been behind in terms of growth as well. At first site, they seem to reveal relatively high levels of MHC diversity. To control for these possible continental differences, we present two sets of estimates in Columns (7)-(10). One set of OLS and 2SLS estimates for the 1960-2000 period excluding Asia and another set excluding the African countries. The estimates for $\alpha_{2}$ remain statistically significant in all these four specifications. In addition, estimating the model using continent dummy variables instead of $O E C D_{c}$, or excluding certain regions from the regression analysis, does not alter the conclusions.

Column (1) of Table VI reports the OLS estimation results of estimating the following model:

$$
\begin{gathered}
\Delta G D P_{c_{1960-2000}}=C+\alpha_{1} G D P_{c_{1960}}+\alpha_{2} H L A-A_{c}+\alpha_{3} P P_{c}+\alpha_{4} L A_{c} \\
+\alpha_{5} H E_{c}+\alpha_{6} I M M_{I}+\alpha_{7} F R_{c}+\alpha_{8} O E C D_{c} \epsilon_{c} .
\end{gathered}
$$

We added the covariats $H E_{c}, I M M_{c}, P P_{c}$ and $L A_{c}$ because differences in health systems and pathogen pressure could potentially have an impact on $\alpha_{2}$. In addition, fractionalization $\left(F R_{c}\right)$ could potentially have an impact as well (e.g., Alesina et al. [2003]). The estimate (standard error) for $\alpha_{2}$ is equal to $-5.192(1.749)$ and significant at the one percent level. Column (2) reports the 2SLS estimate of the same equation. The estimate 
for $\alpha_{2}$ equals $-8.270(3.633)$ and is significant at the five percent level. Finally, we have applied a different measure of economic performance. Using the 2000 log level of GDP per capita yields a similar negative relationship with MHC diversity, as is illustrated in Column (3) of Table VI. Estimating the model using continental dummies instead of an OECD dummy yields similar results. ${ }^{34}$

The body of literature explaining cross-country differences in economic outcomes suggests a number of additional variables explaining economic growth. We have included the most often used covariates in a growth regression. In particular we estimate the following equation

$$
\begin{gathered}
\Delta G D P_{c_{1960-2000}}=C+\alpha_{0} G D P_{c_{1960}}+\alpha_{1} H L A-A_{c}+\alpha_{2} H C_{c}+ \\
\alpha_{3} L E_{c_{1990}}+\alpha_{4} O E C D_{c}+\alpha_{5} H E_{c}+\alpha_{6} I M M_{c}+\alpha_{7} P P_{c}+ \\
\alpha_{8} L A_{c}+\alpha_{9} F R_{c}+\alpha_{10} O T H_{c}+\epsilon_{c}
\end{gathered}
$$

where $O T H_{c}$ is either country c's trade with others, $M_{2} / \mathrm{GDP}$, growth of the labor force, fertility, the investment rate, or gross enrolment in primary and secondary education. Trade is defined as the log difference of imports and exports in 1995 and 1960; $M_{2} /$ GDP is a financial variable suggested by King and Levine [1993] to capture primary financial development measured in 1995; growth of the labor force is defined as the log difference between the population aged 16-65 in 2000 and 1960; fertility is the fertility rate in 1990; investment rate is the price level of investment goods in 1960; and education is measured using Barro's measure of the proportion of eligible students enrolled in secondary and primary education in 1960 (e.g., Barro [1991]).

The results are shown in Table VII where each of the columns reports the inclusion of one of the covariates captured by $O T H_{c}$. The estimate for $\alpha_{1}$ turns out to be relatively insensitive to the inclusion of these covariates and remains statistically significant in all specifications reported.

\section{$5 \quad$ Alternative Explanations}

\subsection{Different Disease Environments}

Potential alternative ways to explain the empirical link between MHC diversity and economic performance could be based on differences in disease environments that affect both the immune system and economic performance. One could think of the distinction between cities and villages or differences in climate, which affect the survival rate of pathogens.

\footnotetext{
${ }^{34}$ Reducing the sample by excluding negatively growing countries, such as Zambia, Congo, Venezuela and Senegal, excluding the high growth countries, such as Singapore, Korea, and Oman, or by excluding the Asian or African countries does not change the main conclusion drawn from Table VI.
} 
Regarding the distinction between cities and villages, more people live close to each other in cities, increasing the probability of infections. Since it is known that cities cause economic growth, the empirical link between economic performance and MHC diversity could be explained if evolutionary forces would reduce MHC diversity in cities. The model shows that with selfish agents pathogen pressure will increase diversity and it is hard to see how urban circumstances could affect this evolutionary equilibrium. Furthermore, in the data we find no correlation between MHC diversity and degree of urbanization at different points in time, while the argument would also require a higher degree of cooperation in cities. $^{35}$

The other way around one could argue that in certain areas a warmer and more humid climate creates an environment that is more favorable to pathogens. For that reason, populations living in such an area will be more vulnerable to infections, and consequently be less productive. It is hard to underpin this alternative explanation theoretically, as it requires an argument that the evolutionary equilibrium of HLA molecules is more diverse in environments with a higher pathogen pressure, while models that stress the importance of diversity will predict maximum diversity in all populations. Also the empirical evidence is not consistent with this explanation, since the link between MHC diversity and economic outcomes is not affected by the inclusion of variables reflecting the health status of the population. This suggests that the link between MHC diversity and economic outcomes is a direct one and not moderated by health outcomes.

\subsection{Benefits of Diversity and "Group Selection"}

The theoretical prediction and empirical observation that - from a social perspective a lower level of MHC diversity is beneficial may strike the reader as a counter-intuitive result. The most likely reason is a general intuitive notion that diversity in general, and especially genetic diversity, is advantageous. It is important to notice that our finding about the social planner's desire to establish a lower level of MHC diversity is related to the specific properties of the immune system and the role of the MHC in the adaptive part of the immune system. In economic life their are many examples in which either diversity or similarity is the preferred equilibrium outcome. The gains from the division of labor reveal (comparative) advantages of different abilities to perform specific tasks, but a population speaking the same language has economic gains as well.

The equilibrium in our model and the estimates emphasizing the societal benefits of lower MHC diversity are consistent with the observation that in immunization programs the individual risk of being hurt by these programs is larger than the individual benefits of protection. At the same time, the social benefits of vaccination are much larger than

\footnotetext{
${ }^{35}$ We addressed this issue by investigating urbanization from 1960 to 2000, but also by using population density figures (corrected for the amount of arable land) back to 1500 .
} 
the individual risk. What is crucial in our model is that mutual dependence shifts the evolutionary trade-off. The fact that the measure we deploy is a diversity measure is just a technical feature of the functioning of the immune system.

Another aspect of this discussion is that genetic diversity is important for the preservation of the ecological system. It is true that species with more genetic diversity have higher probabilities of survival during a very dramatic change of the natural environment. These are not the kinds of episodes we want to emphasize in our model for two reasons. First, if genetic diversity in humans is valuable to prevent us from being wiped out during a dramatic event, it would require diversity in all relevant genes, not only diversity at the MHC. In practice, humans do show some degree of genetic diversity, but the degree of MHC diversity goes far beyond this "natural" level of diversity. Clearly, at the level of the $\mathrm{MHC}$ a different force is at work to preserve the species at stake. Second, even in the case where genetic diversity is beneficial and crucial for survival, it is difficult to imagine that selection forces would significantly alter the level of diversity over a reasonable economic time span. In our model, evolutionary pressure is defined at the individual level. However, the agent's evolutionary success depends on the agents in close vicinity. For the selection of societies with sufficient levels of genetic diversity, a process of group selection would be required. Such a process of group selection implies that selection depends on survival and extinction of complete societies. It remains an open question whether group selection processes are important in explaining (human) evolution, but if they are important these processes will require extremely long periods of time to show an effect. While in general with human generations of about 20 years - a rapidly evolving gene takes at least 10,000 years to become important, group selection processes are likely to evolve with lower levels of evolutionary pressure and will require "generations" (i.e., the time span of the development of a small group of people into a mature society) of hundreds of years, making these processes unobservable for sensible economic analyzes. A reasonable time span for group selection processes would be of the order of magnitude of a couple of million of years. It is therefore more likely that group selection has played a role in the development of primitive species than in the development of differences between contemporary human populations.

\subsection{Epidemics}

An issue that is often put forward is whether a negative relationship between MHC diversity and economic performance can be explained by large epidemics. The argument used is that large epidemics in the past have led to selection of non-susceptible humans resulting in a lower degree of MHC diversity. For example, it has been argued that the low degree of MHC diversity of Native Americans can be related to the diseases brought 
to America by white European immigrants. If epidemic infectious diseases have a direct negative impact on the economic performance of a population, the expected effect would be a positive correlation between MHC diversity and economic performance. If epidemic diseases result in selection, economic performance might improve since the fraction of strong people will increase. However, there is no empirical evidence that populations that suffered large losses in the past due to epidemics are the ones with a higher level of economic performance. In case of a pandemic infectious disease a particular allele should have become dominant in all populations. This is not the case.

\subsection{Migration}

Different populations tend to consist of people with dissimilar forefathers. When a country faces an inflow of many immigrants from countries with different alleles, the degree of MHC diversity in this country will rise. In that case MHC diversity is a reflection of group heterogeneity. A negative relationship between $\mathrm{MHC}$ diversity and economic performance would be found if economic performance benefits from homogeneity. The most interesting country to investigate from this perspective is the United States because it has experienced the most dramatic inflow of people from different European countries. The most obvious comparison is between the white U.S. population and people from Western European countries, such as England, France and Italy. Since the ancestors of U.S. whites are from these countries, the MHC frequencies in the United States should reflect these diverse origins, and MHC diversity in the United States should substantially exceed diversity in these European populations. However, the reverse turns out to be the case: HLAA diversity among the white U.S. population is equal to 0.855 , whereas it is equal to 0.893 in France, 0.874 in Italy, and 0.875 in the United Kingdom, which are significant differences given the 0.035 standard deviation of HLA-A diversity. A similar argument applies to HLA-A diversity in Australia, which equals $0.838 .{ }^{36}$ This observation about diversity in the United States and Australia is consistent with our simulation results that the frequency dependent nature of MHC diversity makes the diversity change relatively fast.

\section{Conclusions and Future Research}

In this paper we have shown that there exists an empirical link between economic circumstances and genetic evolution. We have argued that properties of the MHC turn out to be valid for analyzing such a link. Based on an evolutionary theory of the main properties of

\footnotetext{
${ }^{36}$ The levels of HLA-B diversity in the United States and Australia are comparable to the levels for the continental European countries.
} 
the adaptive immune system, we predict that low levels of MHC diversity minimize the incidence of infectious diseases in a population, while the evolutionary equilibrium with selfish agents leads to maximum levels of diversity. Assuming that populations differ in their degree of cooperation, three important predictions have been made. First, if there exists a discrepancy between the social optimum and the selfish equilibrium, lower levels of MHC diversity in a population should be associated with better health outcomes. Second, if differences in MHC diversity between countries reflect differences in the way people cooperate, MHC diversity should be negatively related to indicators of fairness and trust behavior. Finally, this mechanism only works if cooperative behavior has a higher output relative to carrying out individual projects, so economic performance should correlate negatively with MHC diversity. The model is able to replicate the crucial properties of the observed MHC distribution and based on data of $\mathrm{MHC}$ frequencies in 63 populations we find a significant negative correlation between health outcomes and MHC diversity, and between MHC diversity and indicators of fairness and trust collected from several experiments carried out for different countries. Finally, we find a robust negative correlation between MHC diversity and several measures of economic performance.

The findings presented in this paper are of general interest for the following reasons. In biology the role of HLA has been analyzed at the individual human level in relation to sexual selection and the progression of diseases. The main consensus seems to be that people with rare MHC alleles are better protected against diseases because rare MHC molecules complement the protection already provided by the MHC molecules of others. Furthermore, rare MHC molecules seem to be an individually optimal answer to the danger of host pathogen co-evolution. We have shown that taking into account economic externalities implies that the equilibrium level of MHC diversity runs counter to polymorphism and promotes homogeneity. This is important because it offers an explanation for the observed non-uniform frequencies of HLA alleles within populations, which has to date been unexplained by biologists. In anthropology, researchers have focused on HLA polymorphism to explain linguistic and cultural similarities and disparities between populations. We have added to this that economic conditions are likely to lead to relatively rapid changes in the frequency distribution of the HLA and its degree of population diversity. From the viewpoint of behavioral ecology and behavioral economics (which have focused on the issue of human cooperation by means of communication, monitoring and enforcement of norms) we add that differences in experimental outcomes on trust and cooperation reflect long-term structural differences between populations. Finally, we add to the economics discipline that differences in (long-term) economic performance are at least to some extent structural and related to differences in cooperative behavior.

There are several avenues for future research. First, investigating the human immune system from the perspective of differences between individual and social benefits might 
shed light on the biological question why the level of diversity of HLA-A is generally lower than the level of diversity of HLA-B and why HLA diversity between populations is associated with the existence of one dominant type which differs between different populations. One possible reason could be that the types of diseases HLA-A is protecting against are related to larger externalities than the ones HLA-B is taking care of. Relating the existence of infectious diseases, e.g. the several mutants of HIV, to HLA diversity would be an obvious avenue to proceed. ${ }^{37}$ Second, we have used genetic information for the dominant groups in a country. Comparison of levels of HLA diversity within and between different populations living in the same country or region could reveal information about the level of human cooperation within and between different groups in a society, which could for example complement the study of Henrich et al. [2001] in explaining differences in cooperation. Third, MHC diversity in animals is related to sexual selection and disassortive mating (Reusch et al. [2001]). From economic studies concerning sexual selection we know that economic circumstances such as income inequality affect the sexual selection process significantly (Fernández and Rogerson [2001]). An interesting question to explore is whether or not these external influences also affect MHC polymorphism and a population's long-term health status.

\section{Appendix}

\section{A.I. MHC Data Sources}

In 1991, the organizers of the Eleventh International Histocompatibility Workshop and Conference asked participating laboratories from countries all over the world to collect blood samples from representative samples of populations. Each laboratory received a set of sera to type the various HLA antigens. ${ }^{38}$ Juji et al. [1992] provide detailed information about the sera used, the distribution of the sera to the laboratories, and the procedures for testing blood samples. In this way unique and consistent information about allele frequencies of many ethnic groups has been brought together and carefully documented. We have selected individuals from 72 populations that could potentially be matched to countries based on blood samples of 10,394 persons. The major advantage of this undertaking is that we are able to use data about HLA types of a representative group of (healthy) people in each population, collected using identical typing procedures. To the best of our knowledge there are three alternative sources of HLA frequencies for different human populations. First, Cavalli-Sforza et al. [1994] provide tables for HLA-A and HLA-B frequencies. The main limitation of these data is that only frequencies of alleles found consistently in all populations in the world are reported, because these have been

\footnotetext{
${ }^{37}$ Trachtenberg et al. [2003] and Scherer et al. [2004] - analyzing the association of HLA super-types with HIV disease progression rates in a population of HIV-infected men - have suggested that HIV adapts to the most frequent alleles in a population, providing a selective advantage for those who express rare alleles. Kalinkovich et al. [1998] analyze the activation of particular $\mathrm{T}$ cells in recent Ethiopian immigrants in Israel relative to earlier immigrants and find a process of adaptation within humans.

${ }^{38}$ Because reliability of the sera was regarded crucial for this project, a couple of WHO approved antigens could not be identified by this procedure.
} 
found most relevant for anthropologic purposes. To construct a correct measure of HLA diversity, information about rare alleles is also needed. Second, the National Center for Biotechnology Information (NCBI) in Bethesda MD provides an online database of HLA typing studies classified by population. ${ }^{39}$ Third, a comparable database is provided by Derek Middleton at http://www.allelefrequencies.net/. The main disadvantage of these latter two databases is that methods of typing differ between the several studies documented on these web pages. In addition, many of the studies included in these databases refer to specific and small sub-populations within countries.

For the empirical analysis, we have used all sources but applied the data from the Eleventh International Histocompatibility Workshop and Conference as the primary data source. As a secondary source we have made use of the NCBI data and lastly we added information from http:/ /www.allelefrequencies.net/ for countries not included in the other two data sources. Information from the Netherlands is obtained from a study by Voorter, Drent and Van den Berg-Loonen [2004]. We did not use the information collected by Cavalli-Sforza et al. [1994] because it is impossible to construct a reliable diversity index using these data.

Apart from sampling errors, especially the match between ethnic groups and countries and the method applied for typing the molecules is likely to lead to differences in the measurement of HLA diversity. Data from the Eleventh International Histocompatibility Workshop and Conference are likely to be of a relatively high quality compared to the other sources, since all laboratories have used exactly the same sera for typing HLA and are based on representative samples of the ethnic groups considered for analysis. To investigate the robustness of our findings with respect to potential measurement problems in HLA diversity, we carried out all regressions for countries represented only in the data of the Eleventh International Histocompatibility Workshop and Conference as well. We did not find any significant differences with the empirical results from the complete sample.

The HLA has been measured to represent genetic diversity within one ethnic group rather than diversity within a population. For this reason we matched countries to the HLA diversity of the dominant ethnic group, e.g. for the United States we make use of the HLA diversity among U.S. whites, and to characterize HLA diversity in China we use the Northern Han. This procedure excludes information for several ethnic groups because they refer to a group within a country that is not dominant or to ethnic groups spread over a number of countries. We end up with information about HLA diversity for 62 countries: 43 from the Proceedings of the Eleventh International Histocompatibility Workshop and Conference, 11 from the database of the NCBI and 8 from Derek Middleton's database. We add information from the Netherlands from Voorter, Drent and Van den Berg-Loonen [2004] to complete our sample of 63 countries.

\section{A.II. Estimation of HLA diversity}

Diversity is defined as $1-\sum_{k} F_{k}^{2}$ where $F_{k}$ is the frequency of MHC allele $k$ in the population. Using the distribution of MHC molecules in the sample $\left(\hat{F}_{k}\right)$, to calculate diversity $\sum_{k} F_{k}^{2}$ gives an upward biased estimate, and thus an underestimation of diversity:

$$
E\left(\sum_{k} \hat{F}_{k}^{2}\right)=E\left(\sum_{k}\left(F_{k}+\epsilon_{k}\right)^{2}\right)=\sum_{k} F_{k}^{2}-\sum_{k} E\left(\epsilon_{k}^{2}\right) .
$$

\footnotetext{
${ }^{39}$ See http://www.ncbi.nlm.nih.gov/IEB/Research/GVWG/IHWG/ihwg.cgi?ID=9\&cmd=PRJOV.
} 
We approximate

$$
E\left(\epsilon_{k}^{2}\right)=\frac{F_{k}\left(1-F_{k}\right)}{n}
$$

with

$$
\frac{\hat{F}_{k}\left(1-\hat{F}_{k}\right)}{n}
$$

and subtract this expected bias from the diversity in the sample to obtain an estimate of the diversity in the population. Simulation for distributions of HLA-A and HLA-B molecules similar to those observed in the data reveals that this procedure reduces the bias almost completely.

\section{A.III. Data Definitions and Sources}

Table AI presents an overview of the variables, the sources and definitions used in the paper. Measures of MHC diversity are described and defined above.

\section{A.IV. Information from the Games}

Tables AII and AIII provide the studies we have used to construct the sample of offer rates in ultimatum games and the amounts of money sent in trust games.

\section{References}

Alesina, Alberto, Arnaud Devleeschauwer, William Easterly, Sergio Kurlat, and Romain Wacziarg, "Fractionalization," Journal of Economic Growth, VIII (2003), 155-194.

Aoki, Kenichi, "Time Required for Gene Frequency Change in a Deterministic Model of Gene Culture Coevolution, With Special Reference to the Lactose Absorption Problem," Theoretical Population Biology, XL (1991), 354-368.

Barro, Robert J., "Economic Growth in a Cross-Section of Nations," Quarterly Journal of Economics, CVI (1991), 407-443.

Berg, Joyce, John Dickhaut, and Kevin McCabe, "Trust, Reciprocity and Social History," Games and Economic Behavior, X (1995), 122-142.

Bohnet, Iris, and Richard Zeckhauser, "Turst, Risk and Betrayal," Journal of Economic Behavior \&f Organization, LV (2004), 467-484.

Borghans, José A. M., Joost B. Beltman, and Rob J. de Boer, "MHC Polymorphism Under Host-Pathogen Coevolution," Immunogenetics, LV (2004), 732-739.

Camerer, Colin F., "Strategizing in the Brain," Science, CCC (2003), 1673-1675. 
Carrington, Mary, and Stephen J. O'Brien, "The Influence of HLA Genotype on AIDS," Annual Review of Medicine, LIV (2003), 535-551.

Cavalli-Sforza, Luigi Luca, Paolo Menozzi, and Alberto Piazza, The History and Geography of Human Genes (Princeton University Press, Princeton NJ, 1994).

Charness, Gary, and Matthew Rabin, "Understanding Social Preferences with Simple Tests," Quarterly Journal of Economics, CXVII (2002), 817-869.

de Boer, Rob J., José A.M. Borghans, Michiel van Boven, Can Kesmir, and Franz J. Weissing, "Heterozygote Advantage Fails to Explain the High Degree of Polymorphism of the MHC," Immunogenetics, LV (2004), 725-731.

Dolan, Raymond J., "Emotion, Cognition, and Behavior," Science, CCXCVIII (2002), 1191-1194.

Durham, William H., Coevolution: Genes, Culture, and Human Diversity (Stanford University Press, San Francisco CA, 1992).

Fehr, Ernst, and Urs Fischbacher, "The Nature of Human Altruism," Nature, CDXXV (2003), 785-791.

Fehr, Ernst, and Klaus M. Schmidt, "A Theory of Fairness, Competition, and Cooperation," Quarterly Journal of Economics, CXIV (1999), 817-868.

Fernández, Raquel, and Richard D. Rogerson, "Sorting and Long-Run Inequality," Quarterly Journal of Economics, CXVI (2001), 1305-1341.

Gallup, John L., Mellinger, Andrew, and Sachs, Jeffrey D., "Geography Datasets," Center for International Development, Harvard University, 2001.

Galor, Oded, and Omer Moav, "Natural Selection and the Evolution of Life Expectancy," Working Paper Brown/Hebrew University, August 2004.

Gütz, Werner, and Reinhard Tietz, "Ultimatum Bargaining Behavior: A Survey and Comparison of Experimental Results," Journal of Economic Psychology, XI (1990), 417449.

Hall, Robert E., and Charles I. Jones, "Why Do Some Countries Produce So Much More Output per Worker than Others?" Quarterly Journal of Economics, CXIV (1999), 83-116.

Hansen, Ted H., and David H. Sachs, "The Major Histocompatibility Complex," in: William E. Paul (ed.), Fundamental Immunology, Second Edition (Raven Press Ltd., New York NY, 1989), 445-487.

Henrich, Joseph, Robert Boyd, Samuel Bowles, Colin F. Camerer, Ernst Fehr, Herbert Gintis, and Richard McElreath, "In Search of Homo Economicus: Behavioral Experiments 
in 15 Small-Scale Societies," American Economic Review, XCI (2001), 73-78.

Hewlett, Barry S., Annalisa De Silvestri, and C. Rosalba Guglielmino, "Semes and Genes in Africa," Current Anthropology, XLIII (2002), 313-321.

Hill, Adrian V.S., Catherine E.M. Allsopp, Dominic Kwiatkowski, Nicholas M. Anstey, Patrick Twumasi, Pamela A. Rowe, Stephen Bennett, David Brewster, Andrew J. McMichael, and Brian M. Greenwood, "Common West African HLA Antigens Are Associated with Protection from Severe Malaria," Nature, CCCLII (1991), 595-600.

Holt, Charles A. and Susan K. Laury, "Risk Aversion and Incentive Effects," American Economic Review, XCII (2002), 1644-1655.

Hong, Kessely, and Iris Bohnet, "Status and Distrust: The Relevance of Inequality and Betrayal Aversion," Working Paper, JFK School of Government, September 2004.

Juji, Takeo, Tatsuya Akaza, Katsushi Tokunaga, Hiromi Miyoshi, and Kouichi Kashiwase, "The Serology Studies of the Eleventh International Histocompatability Workshop: An Overview," in: Kimiyoshi Tsuji, Miki Aizawa, and Takehiko Sasazuki (eds.), Proceedings of the Eleventh International Histocompatibility Workshop and Conference, (Oxford: Oxford University Press, 1992), 83-108.

Kalinkovich, A., Z. Weisman, Z. Greenberg, J. Nahmia, S. Eitan, M. Stein, and R. Bentwich, "Decreased CD4 and Increased CD8 Counts with Cell Activation Is Associated with Chronic Helminth Infection," Clinical Experimental Immunology, CXIV (1998), 414421.

Kiepiela, Photini, Alasdair J. Leslie, Isobella Honeyborne, Danni Ramduth, Christina Thobakgale, Senica Chetty, Prinisha Rathnavalu, Corey Moore, Katja J. Pfafferott, Louise Hilton, Peter Zimbwa, Sarah Moore, Todd Allen, Christian Brander, Marylyn M. Addo, Marcus Altfeld, Ian James, Simon Mallal, Michael Bunce, Linda D. Barber, James Szinger, Cheryl Day, Paul Klenerman, James Mullins, Bette Korber, Hoosen M. Coovadia, Bruce D. Walker, and Philip J.R. Goulder (2004), "Dominant Influence of HLA-B in Mediating the Potential Co-Evolution of HIV and HLA," Nature, CDXXXII (2004), 769-774.

King, Robert G., and Ross Levine, "Finance and Growth: Schumpeter Might Be Right," Quarterly Journal of Economics, CVIII (1993), 717-737.

Kosfeld, Michael, Markus Heinrichs, Paul J. Zak, Urs Fischbacher, and Ernst Fehr, "Oxytocin Increases Trust in Humans," Nature, CDXXXV (2005), 673-676.

Lund, Ole, Morten Nielsen, Can Kesmir, Anders Gorm Petersen, Claus Lundegaard, Peter Worning, Christina Sylverster-Hvid, Kasper Lamberth, Gustav Rder, Sune Justesen, Sren Buus, and Sren Brunak, "Definition of Supertypes for HLA Molecules Using Clustering of Specificity Matrices," Immunogenetics, LV (2004), 797-810.

Maynard Smith, John, and George R. Price, "The Logic of Animal Conflict," Nature, 
CCXLVI (1973), 15-18.

Milinski, Manfred, and Claus Wedekind, "Evidence for MHC-Correlated Perfume Preferences in Humans," Behavioral Ecology, XII (2001), 140-149.

Oosterbeek, Hessel, Randolph Sloof, and Gijs van de Kuilen, "Cultural Differences in Ultimatum Game Experiments: Evidence from a Meta-Analysis," Experimental Economics, VII (2004), 171-188.

Penn, Dustin J., "The Scent of Genetic Compatibility: Sexual Selection and the Major Histocompatibility Complex," Ethology, CVIII (2002), 1-21.

Playfair, John H.L., and Gregory J. Bancroft, Infection and Immunity (Oxford University Press, Oxford, 2004).

Reusch, Thorsten B.H., Michael A. Haberli, Peter B. Aeschlimann, and Manfred Milinski, "Female Sticklebacks Count Alleles in a Strategy of Selection Explaining MHC Polymorphism," Nature, CDXIV (2001), 300-302.

Robinson, Mary Ann, and Thomas J. Kindt, "Major Histocompatibility Complex and Genes," in: William E. Paul (ed.), Fundamental Immunology, Second Edition (Raven Press Ltd., New York NY, 1989), 489-539.

Roth, Alvin E., and Ido Erev, "Learning in Extensive-Form Games: Experimental Data and Simple Dynamic Models in the Intermediate Term," Games and Economic Behavior, VIII (1995), 164-212.

Roth, Alvin E., Vesna Prasnikar, Masahiro Okuno-Fujiwara, and Shmuel Zamir, "Bargaining and Market Behavior in Jerusalem, Ljubljana, Pittsburgh, and Tokyo: An Experimental Study," American Economic Review, CXXXI (1991), 1068-1095.

Scherer, Almut, John Frater, Annette Oxenius, Juliet Agudelo, David A. Price, Huldrych F. Günthard, Martin Barnardo, Luc Perrin, Bernard Hirschel, Rodney E. Phillips, Angela R. McLean, and the Swiss HIV Cohort Study, "Quantifiable Cytotoxic T Lymphocyte Responses and HLA-Related Risk of Progression to AIDS," Proceedings of the National Academy of Sciences USA, CI (2004), 12266-12270.

Saint-Paul, Gilles, "On Market Forces and Human Evolution," Working Paper, Toulouse, July 2003.

Sette, Alessandro, and John Sidney, "Nine Major HLA Class I Supertypes Account for the Vast Preponderance of HLA-A and -B Polymorphism," Immunogenetics, L (1999), 201-212.

Slonim, Robert L., and Alvin E. Roth, "Learning in High Stakes Ultimatum Games: An Experiment in the Slovak Republic," Econometrica, CXVI (1998), 569-596. 
Trachtenberg, Elizabeth, Bette Korber, Cristina Sollars, Thomas B. Kepler, Peter T. Hraber, Elizabeth Hayes, Robert Funkhouser, Michael Fugate, James Theiler, Yen S. Hsu, Kevin Kunstman, Samuel Wu, John Phair, Henry Erlich, and Steven Wolinsky, "Advantage of Rare HLA Supertype in HIV Disease Progression," Nature Medicine, IX (2003), 928-935.

Van Damme, Eric, Stability and Perfection of Nash Equilibria (Springer Verlag, Berlin, 1991).

Voorter, Cristina E.M., Marjolein Drent, and Ella M. van den Berg-Loonen, "Severe Pulmonary Sarcoidosis is Strongly Associated with HLA-DQB1*0602," Working Paper, Maastricht University, 2004.

Wedekind, Claus, and S. Füri, "Body Odor Preferences in Men and Women: Do They Aim for Specific MHC Combinations or Simple Heterogeneity?," Proceedings of the Royal Society of London, Series B, CCLXIV (1997), 1471-1479. 
Table I

Simulation Results of the Pace of Change of the Evolutionary Process

\begin{tabular}{|c|c|c|c|c|}
\hline & (1) & (2) & (3) & (4) \\
\hline & Before & After & Difference & Fitness immediately after change \\
\hline Diversity & 0.700 & 0.600 & & \\
\hline MHC-1 & 35.98 & 49.00 & +13.02 & 1.0500 \\
\hline MHC-2 & 34.24 & 38.84 & +4.60 & 1.0428 \\
\hline MHC-3 & 21.61 & 8.95 & -12.66 & 0.9797 \\
\hline MHC-4 & 8.17 & 3.21 & -4.96 & 0.9275 \\
\hline Percentage changing alleles & & & 17.62 & \\
\hline
\end{tabular}

Note: We used the following parameters: $n=10, m=6, \bar{p}_{\text {low }}=0.1, \bar{p}_{\text {high }}=0.6, q_{\text {low }}=0.1, q_{\text {high }}=0.6$, and $\alpha=0.1$. 
Table II

The Relationship between Offer Rates from Ultimatum and Sent Money in Trust Games and MHC Diversity (Dependent Variables: Offer and Sent Rates)

\begin{tabular}{|c|c|c|c|c|c|c|c|c|c|c|}
\hline & \multicolumn{5}{|c|}{ Offer Rates in Ultimatum Games } & \multicolumn{5}{|c|}{ Sent Money in Trust Games } \\
\hline & (1) & $(2)$ & (3) & (4) & $(5)$ & (6) & (7) & $(8)$ & $(9)$ & $(10)$ \\
\hline & OLS & OLS & OLS & OLS & 2SLS & OLS & OLS & OLS & OLS & 2SLS \\
\hline & HLA-A & HLA-A & HLA-B & HLA-B & HLA-A & HLA-A & HLA-A & HLA-B & HLA-B & HLA-A \\
\hline$M H C_{i}$ & $\begin{array}{r}-131.628 \\
(35.124)\end{array}$ & $\begin{array}{r}-143.895 \\
(41.369)\end{array}$ & $\begin{array}{r}-137.943 \\
(72.124)\end{array}$ & $\begin{array}{c}-220.386 \\
(136.165)\end{array}$ & $\begin{array}{l}-200.727 \\
(100.477)\end{array}$ & $\begin{array}{c}-227.988 \\
(62.267)\end{array}$ & $\begin{array}{l}-209.211 \\
(89.662)\end{array}$ & $\begin{array}{l}-192.587 \\
(154.086)\end{array}$ & $\begin{array}{l}-241.725 \\
(200.587)\end{array}$ & $\begin{array}{c}-285.897 \\
(192.587)\end{array}$ \\
\hline Controls & No & Yes & No & Yes & Yes & No & Yes & No & Yes & Yes \\
\hline Adj. $\mathrm{R}^{2}$ & 0.272 & 0.287 & 0.125 & 0.089 & 0.223 & 0.383 & 0.437 & 0.058 & 0.047 & 0.078 \\
\hline$n$ & 23 & 23 & 23 & 23 & 23 & 21 & 21 & 21 & 21 & 21 \\
\hline
\end{tabular}

Note: Standard errors are reported in brackets. The instrument used for HLA -A diversity in the 2SLS estimates is HLA - B diversity. The control variables in the regressions using the offer rates from ultimatum games as the dependent variable are a dummy variable for the type of game, the stakes relative to GDP per capita, a dummy for students being subjects and an OECD dummy. In the regressions using the sent money in trust games as the dependent variable we included an OECD dummy, the stakes relative to GDP per capita, a dummy for students being subjects, a dummy for the investor and trustee receiving an initial endowment or only the investor, and a dummy for tripling or doubling the sent money. 
Table III

Health Outcomes and MHC Diversity

(Dependent Variable: Life Expectancy at Birth in 1990)

\begin{tabular}{|c|c|c|c|c|c|c|}
\hline & (1) & (2) & (3) & (4) & (5) & (6) \\
\hline & OLS & OLS & OLS & OLS & 2SLS & 2SLS \\
\hline & HLA-A & HLA-B & HLA-A & HLA-B & HLA-A & HLA-A \\
\hline$M H C_{i}$ & $\begin{array}{r}-40.045 \\
(14.942 \\
\end{array}$ & $\begin{array}{c}-91.208 \\
(32.744)\end{array}$ & $\begin{array}{l}-47.145 \\
(14.434)\end{array}$ & $\begin{array}{r}-111.278 \\
(31.998) \\
\end{array}$ & $\begin{array}{l}-44.795 \\
(23.562)\end{array}$ & $\begin{array}{l}-95.562 \\
(30.527) \\
\end{array}$ \\
\hline$P P_{i}$ & $\begin{array}{c}-5.393 \\
(1.033)\end{array}$ & $\begin{array}{l}-5.325 \\
(1.027)\end{array}$ & $\begin{array}{l}-5.085 \\
(1.029)\end{array}$ & $\begin{array}{c}-5.128 \\
(1.031)\end{array}$ & $\begin{array}{c}-2.627 \\
(0.972)\end{array}$ & $\begin{array}{c}-5.274 \\
(1.138)\end{array}$ \\
\hline$L A_{i}$ & $\begin{array}{c}-0.153 \\
(0.058)\end{array}$ & $\begin{array}{c}-0.171 \\
(0.058)\end{array}$ & $\begin{array}{c}-0.132 \\
(0.058)\end{array}$ & $\begin{array}{c}-0.159 \\
(0.059)\end{array}$ & $\begin{array}{c}-0.109 \\
(0.046)\end{array}$ & $\begin{array}{c}-0.137 \\
(0.064)\end{array}$ \\
\hline$H E_{i}$ & $\begin{array}{c}3.082 \\
(0.668)\end{array}$ & $\begin{array}{c}3.063 \\
(0.666)\end{array}$ & $\begin{array}{c}1.755 \\
(0.901)\end{array}$ & $\begin{array}{c}1.651 \\
(0.911)\end{array}$ & $\begin{array}{c}1.847 \\
(0.594)\end{array}$ & $\begin{array}{c}1.263 \\
(1.022)\end{array}$ \\
\hline$I M M_{i}$ & $\begin{array}{c}0.111 \\
(0.046)\end{array}$ & $\begin{array}{c}0.150 \\
(0.045)\end{array}$ & $\begin{array}{c}0.105 \\
(0.046)\end{array}$ & $\begin{array}{c}0.156 \\
(0.045)\end{array}$ & $\begin{array}{c}0.079 \\
(0.050)\end{array}$ & $\begin{array}{c}0.105 \\
(0.055)\end{array}$ \\
\hline$G D P_{i 1960}$ & & & $\begin{array}{c}1.873 \\
(0.818)\end{array}$ & $\begin{array}{c}1.942 \\
(0.828)\end{array}$ & & $\begin{array}{c}2.184 \\
(0.915)\end{array}$ \\
\hline$O E C D_{i}$ & Yes & Yes & Yes & Yes & Yes & Yes \\
\hline$\underset{n}{\operatorname{Adj} .} \mathrm{R}^{2}$ & $\begin{array}{c}0.726 \\
63\end{array}$ & $\begin{array}{c}0.728 \\
63\end{array}$ & $\begin{array}{c}0.755 \\
62\end{array}$ & $\begin{array}{c}0.756 \\
62\end{array}$ & $\begin{array}{c}0.582 \\
63\end{array}$ & $\begin{array}{c}0.717 \\
62\end{array}$ \\
\hline $\begin{array}{l}\text { Predicted effect of a one-standard deviation } \\
\text { increase in MHC diversity }\end{array}$ & -0.184 & -0.189 & -0.216 & -0.230 & -0.205 & -0.438 \\
\hline $\begin{array}{l}\text { Predicted effect of } 10 \text { point increase in } \\
\text { MHC diversity }\end{array}$ & -0.521 & -1.186 & -0.613 & -1.447 & -0.582 & -1.242 \\
\hline
\end{tabular}

Note: Variables are defined in the Appendix. Standard errors are reported in brackets. The instrument used for HLA -A diversity in the estimates reported in Columns (5) and (6) is HLA -B diversity. 
Table IV

Infectious Diseases and MHC Diversity

(Dependent Variable: Fraction of the Population Died From Viral Infections in 2000 (Multiplied by 1,000))

\begin{tabular}{|c|c|c|c|c|c|c|}
\hline & $\begin{array}{l}(1) \\
\text { OLS }\end{array}$ & $\begin{array}{l}\text { (2) } \\
\text { OLS }\end{array}$ & $\begin{array}{l}\text { (3) } \\
\text { OLS }\end{array}$ & $\begin{array}{c}(4) \\
\text { OLS }\end{array}$ & $\begin{array}{c}(5) \\
\text { 2SLS }\end{array}$ & $\begin{array}{c}(6) \\
\text { 2SLS }\end{array}$ \\
\hline & HLA-A & HLA-B & HLA-A & HLA-B & HLA-A & HLA-A \\
\hline$M H C_{i}$ & $\begin{array}{c}0.326 \\
(0.083) \\
\end{array}$ & $\begin{array}{c}0.649 \\
(0.182) \\
\end{array}$ & $\begin{array}{c}0.330 \\
(0.081) \\
\end{array}$ & $\begin{array}{c}0.620 \\
(0.183) \\
\end{array}$ & $\begin{array}{c}0.460 \\
(0.130) \\
\end{array}$ & $\begin{array}{c}0.438 \\
(0.125) \\
\end{array}$ \\
\hline$P P_{i}$ & $\begin{array}{c}0.013 \\
(0.006)\end{array}$ & $\begin{array}{c}0.011 \\
(0.006)\end{array}$ & $\begin{array}{c}0.010 \\
(0.006)\end{array}$ & $\begin{array}{c}0.008 \\
(0.007)\end{array}$ & $\begin{array}{c}0.015 \\
(0.007)\end{array}$ & $\begin{array}{c}0.011 \\
(0.007)\end{array}$ \\
\hline$L A_{i}$ & $\begin{array}{c}0.000 \\
(0.000)\end{array}$ & $\begin{array}{c}0.000 \\
(0.000)\end{array}$ & $\begin{array}{c}0.000 \\
(0.000)\end{array}$ & $\begin{array}{c}0.000 \\
(0.000)\end{array}$ & $\begin{array}{c}0.000 \\
(0.000)\end{array}$ & $\begin{array}{c}0.000 \\
(0.000)\end{array}$ \\
\hline$H E_{i}$ & $\begin{array}{l}-0.007 \\
(0.004)\end{array}$ & $\begin{array}{l}-0.008 \\
(0.004)\end{array}$ & $\begin{array}{l}-0.011 \\
(0.006)\end{array}$ & $\begin{array}{l}-0.013 \\
(0.006)\end{array}$ & $\begin{array}{l}-0.005 \\
(0.004)\end{array}$ & $\begin{array}{l}-0.012 \\
(0.006)\end{array}$ \\
\hline$I M M_{i}$ & $\begin{array}{c}0.000 \\
(0.001)\end{array}$ & $\begin{array}{c}0.001 \\
(0.000)\end{array}$ & $\begin{array}{c}0.000 \\
(0.000)\end{array}$ & $\begin{array}{c}0.000 \\
(0.000)\end{array}$ & $\begin{array}{c}0.000 \\
(0.000)\end{array}$ & $\begin{array}{c}0.000 \\
(0.000)\end{array}$ \\
\hline$G D P_{i 1960}$ & & & $\begin{array}{c}0.007 \\
(0.005)\end{array}$ & $\begin{array}{c}0.007 \\
(0.006)\end{array}$ & & $\begin{array}{c}0.007 \\
(0.005)\end{array}$ \\
\hline$O E C D_{i}$ & Yes & Yes & Yes & Yes & Yes & Yes \\
\hline $\begin{array}{l}\text { Adj. } \mathrm{R}^{2} \\
n\end{array}$ & $\begin{array}{c}0.391 \\
47 \\
\end{array}$ & $\begin{array}{c}0.361 \\
47 \\
\end{array}$ & $\begin{array}{c}0.307 \\
46 \\
\end{array}$ & $\begin{array}{c}0.387 \\
46 \\
\end{array}$ & $\begin{array}{c}0.357 \\
47 \\
\end{array}$ & $\begin{array}{c}0.402 \\
46 \\
\end{array}$ \\
\hline $\begin{array}{l}\text { Pred. effect of a one-standard deviation } \\
\text { increase in MHC diversity }\end{array}$ & 0.493 & 0.444 & 0.500 & 0.424 & 0.696 & 0.663 \\
\hline $\begin{array}{l}\text { Pred. effect of } 10 \text { point increase in } \\
\text { MHC diversity }\end{array}$ & 1.400 & 2.787 & 1.417 & 2.663 & 1.976 & 1.881 \\
\hline
\end{tabular}

Note: Variables are defined in the Appendix. Standard errors are reported in brackets. The instrument used for HLA-A diversity in the estimates reported in Columns (5) and (6) is HLA-B diversity. 
Table V

Economic Performance and HLA-A Diversity

(Dependent Variables: GDP per Capita Growth for the Indicated Periods)

\begin{tabular}{|c|c|c|c|c|c|c|c|c|c|c|}
\hline & \multicolumn{6}{|c|}{ Full Sample } & \multicolumn{2}{|c|}{ Excluding Africa } & \multicolumn{2}{|c|}{ Excluding Asia } \\
\hline & $\begin{array}{c}(1) \\
1960-2000 \\
\text { OLS } \\
\end{array}$ & $\begin{array}{c}(2) \\
1970-2000 \\
\text { OLS } \\
\end{array}$ & $\begin{array}{c}(3) \\
1980-2000 \\
\text { OLS } \\
\end{array}$ & $\begin{array}{c}(4) \\
1960-2000 \\
\text { 2SLS } \\
\end{array}$ & $\begin{array}{c}(5) \\
1970-2000 \\
\text { 2SLS } \\
\end{array}$ & $\begin{array}{c}(6) \\
1980-2000 \\
2 S L S \\
\end{array}$ & $\begin{array}{c}(7) \\
1960-2000 \\
\text { OLS } \\
\end{array}$ & $\begin{array}{c}(8) \\
1960-2000 \\
2 S L S \\
\end{array}$ & $\begin{array}{c}(9) \\
1960-2000 \\
\text { OLS } \\
\end{array}$ & $\begin{array}{c}(10) \\
1960-2000 \\
2 S L S \\
\end{array}$ \\
\hline$M H C_{i}$ & $\begin{array}{l}-7.589 \\
(2.011)\end{array}$ & $\begin{array}{l}-6.412 \\
(1.779)\end{array}$ & $\begin{array}{l}-4.609 \\
(1.329)\end{array}$ & $\begin{array}{l}-10.705 \\
(4.133)\end{array}$ & $\begin{array}{l}-6.180 \\
(3.535)\end{array}$ & $\begin{array}{l}-5.925 \\
(2.712)\end{array}$ & $\begin{array}{l}-7.939 \\
(1.808)\end{array}$ & $\begin{array}{c}-13.030 \\
(4.303)\end{array}$ & $\begin{array}{c}-5.499 \\
(2.449)\end{array}$ & $\begin{array}{c}-6.287 \\
(3.818)\end{array}$ \\
\hline Initial $G D P_{i}$ & $\begin{array}{c}-0.093 \\
(0.080)\end{array}$ & $\begin{array}{c}-0.108 \\
(0.077)\end{array}$ & $\begin{array}{c}-0.117 \\
(0.053)\end{array}$ & $\begin{array}{c}-0.095 \\
(0.081)\end{array}$ & $\begin{array}{c}-0.108 \\
(0.077)\end{array}$ & $\begin{array}{c}-0.118 \\
(0.053)\end{array}$ & $\begin{array}{c}-0.118 \\
(0.071)\end{array}$ & $\begin{array}{c}-0.105 \\
(0.077)\end{array}$ & $\begin{array}{c}-0.115 \\
(0.084)\end{array}$ & $\begin{array}{c}-0.113 \\
(0.085)\end{array}$ \\
\hline Adj. $R^{2}$ & 0.191 & 0.209 & 0.212 & 0.099 & 0.069 & 0.128 & 0.285 & 0.159 & 0.151 & 0.129 \\
\hline$n$ & 62 & 53 & 61 & 62 & 53 & 61 & 52 & 52 & 53 & 53 \\
\hline
\end{tabular}

Note: Variables are defined in the Appendix. Standard errors are reported in brackets. The instrument used for HLA -A diversity in the 2SLS estimates is HLA -B diversity. 
Table VI

Economic Performance and HLA-A Diversity Including Covariates (Dependent Variables: GDP per Capita (Growth) for the Indicated Periods)

\begin{tabular}{|c|c|c|c|}
\hline & $\begin{array}{c}(1) \\
1960-2000 \\
\text { OLS } \\
\end{array}$ & $\begin{array}{c}(2) \\
1960-2000 \\
2 S L S \\
\end{array}$ & $\begin{array}{c}(3) \\
2000 \\
\text { OLS } \\
\end{array}$ \\
\hline$M H C_{i}$ & $\begin{array}{l}-5.192 \\
(1.749)\end{array}$ & $\begin{array}{l}-8.270 \\
(3.633)\end{array}$ & $\begin{array}{l}-4.971 \\
(2.323)\end{array}$ \\
\hline Initial $G D P_{i}$ & $\begin{array}{l}-0.425 \\
(0.108)\end{array}$ & $\begin{array}{l}-0.390 \\
(0.116)\end{array}$ & \\
\hline$P P_{i}$ & $\begin{array}{l}-0.147 \\
(0.143)\end{array}$ & $\begin{array}{l}-0.174 \\
(0.149)\end{array}$ & $\begin{array}{l}-0.079 \\
(0.176)\end{array}$ \\
\hline$L A_{i}$ & $\begin{array}{c}-0.017 \\
(0.008)\end{array}$ & $\begin{array}{l}-0.017 \\
(0.008)\end{array}$ & $\begin{array}{l}-0.013 \\
(0.010)\end{array}$ \\
\hline$H E_{i}$ & $\begin{array}{c}0.410 \\
(0.111)\end{array}$ & $\begin{array}{c}0.376 \\
(0.119)\end{array}$ & $\begin{array}{c}0.786 \\
(0.106)\end{array}$ \\
\hline$I M M_{i}$ & $\begin{array}{c}0.011 \\
(0.005)\end{array}$ & $\begin{array}{c}0.009 \\
(0.006)\end{array}$ & $\begin{array}{c}0.005 \\
(0.007)\end{array}$ \\
\hline$F R_{i}$ & $\begin{array}{l}-0.937 \\
(0.348)\end{array}$ & $\begin{array}{l}-0.934 \\
(0.359)\end{array}$ & $\begin{array}{l}-0.901 \\
(0.341)\end{array}$ \\
\hline$O E C D_{i}$ & Yes & Yes & Yes \\
\hline Adj. $R^{2}$ & 0.489 & 0.457 & 0.852 \\
\hline$n$ & 60 & 60 & 60 \\
\hline
\end{tabular}

Note: Variables are defined in the Appendix. Standard errors are reported in brackets. The instrument used for HLA-A diversity in the 2SLS estimates is HLA-B diversity. 
Table VII

Robustness to the Inclusion of Other Covariates

(Dependent Variables: GDP per Capita Growth 1960-2000)

\begin{tabular}{|c|c|c|c|c|c|c|}
\hline & (1) & (2) & (3) & (4) & (5) & (6) \\
\hline & OLS & OLS & OLS & OLS & OLS & OLS \\
\hline$M H C_{i}$ & $\begin{array}{c}-4.195 \\
(1.430)\end{array}$ & $\begin{array}{c}-3.888 \\
(1.808)\end{array}$ & $\begin{array}{c}-6.321 \\
(1.737)\end{array}$ & $\begin{array}{c}-6.067 \\
(1.768)\end{array}$ & $\begin{array}{c}-6.308 \\
(1.669)\end{array}$ & $\begin{array}{c}-5.493 \\
(1.824)\end{array}$ \\
\hline Initial $G D P_{i}$ & $\begin{array}{c}-0.465 \\
(0.078)\end{array}$ & $\begin{array}{c}-0.474 \\
(0.093)\end{array}$ & $\begin{array}{c}-0.505 \\
(0.108)\end{array}$ & $\begin{array}{c}-0.455 \\
(0.106)\end{array}$ & $\begin{array}{c}-0.432 \\
(0.097)\end{array}$ & $\begin{array}{c}-0.470 \\
(0.099)\end{array}$ \\
\hline$L E_{i}$ & $\begin{array}{c}0.014 \\
(0.018)\end{array}$ & $\begin{array}{c}0.003 \\
(0.015)\end{array}$ & $\begin{array}{c}-0.011 \\
(0.016)\end{array}$ & $\begin{array}{c}-0.018 \\
(0.021)\end{array}$ & $\begin{array}{c}-0.012 \\
(0.015)\end{array}$ & $\begin{array}{c}-0.009 \\
(0.017)\end{array}$ \\
\hline$H C_{i}$ & $\begin{array}{c}-0.439 \\
(0.347)\end{array}$ & $\begin{array}{c}-0.099 \\
(0.476)\end{array}$ & $\begin{array}{c}0.316 \\
(0.424)\end{array}$ & $\begin{array}{c}0.395 \\
(0.430)\end{array}$ & $\begin{array}{c}0.347 \\
(0.405)\end{array}$ & $\begin{array}{c}0.317 \\
(0.431)\end{array}$ \\
\hline$H E_{i}$ & $\begin{array}{c}0.240 \\
(0.095)\end{array}$ & $\begin{array}{c}0.456 \\
(0.107)\end{array}$ & $\begin{array}{c}0.602 \\
(0.120)\end{array}$ & $\begin{array}{c}0.550 \\
(0.124)\end{array}$ & $\begin{array}{c}0.601 \\
(0.110)\end{array}$ & $\begin{array}{c}0.587 \\
(0.118)\end{array}$ \\
\hline$I M M_{i}$ & $\begin{array}{c}0.001 \\
(0.005)\end{array}$ & $\begin{array}{c}-0.005 \\
(0.006)\end{array}$ & $\begin{array}{c}-0.003 \\
(0.006)\end{array}$ & $\begin{array}{c}-0.003 \\
(0.006)\end{array}$ & $\begin{array}{c}-0.002 \\
(0.006)\end{array}$ & $\begin{array}{c}-0.002 \\
(0.006)\end{array}$ \\
\hline$P P_{i}$ & $\begin{array}{c}-0.020 \\
(0.095)\end{array}$ & $\begin{array}{c}-0.002 \\
(0.123)\end{array}$ & $\begin{array}{c}-0.128 \\
(0.128)\end{array}$ & $\begin{array}{c}-0.148 \\
(0.131)\end{array}$ & $\begin{array}{c}-0.107 \\
(0.124)\end{array}$ & $\begin{array}{c}-0.125 \\
(0.130)\end{array}$ \\
\hline$L A_{i}$ & $\begin{array}{c}0.001 \\
(0.007)\end{array}$ & $\begin{array}{c}-0.009 \\
(0.006)\end{array}$ & $\begin{array}{c}-0.012 \\
(0.008)\end{array}$ & $\begin{array}{c}-0.016 \\
(0.007)\end{array}$ & $\begin{array}{c}-0.013 \\
(0.006)\end{array}$ & $\begin{array}{c}-0.014 \\
(0.007)\end{array}$ \\
\hline$F R_{i}$ & $\begin{array}{c}-0.451 \\
(0.251) \\
\end{array}$ & $\begin{array}{c}-0.436 \\
(0.302) \\
\end{array}$ & $\begin{array}{c}-0.777 \\
(0.297) \\
\end{array}$ & $\begin{array}{c}-0.759 \\
(0.300) \\
\end{array}$ & $\begin{array}{c}-0.839 \\
(0.289) \\
\end{array}$ & $\begin{array}{c}-0.729 \\
(0.308) \\
\end{array}$ \\
\hline & Trade & $\mathrm{M}_{2} / \mathrm{GDP}$ & Lab. For. & Fertility & Investment & Education \\
\hline $\mathrm{OTH}_{i}$ & $\begin{array}{c}-0.137 \\
(0.149)\end{array}$ & $\begin{array}{c}0.008 \\
(0.002)\end{array}$ & $\begin{array}{c}0.170 \\
(0.214)\end{array}$ & $\begin{array}{c}-0.043 \\
(0.109)\end{array}$ & $\begin{array}{c}-0.208 \\
(0.107)\end{array}$ & $\begin{array}{c}0.164 \\
(0.082)\end{array}$ \\
\hline$O E C D_{i}$ & Yes & Yes & Yes & Yes & Yes & Yes \\
\hline Adj. $R^{2}$ & 0.755 & 0.704 & 0.565 & 0.559 & 0.595 & 0.561 \\
\hline$n$ & 29 & 39 & 53 & 53 & 53 & 53 \\
\hline
\end{tabular}

Note: Variables are defined in the Appendix. Standard errors are reported in brackets. 


\section{Table AI \\ Definitions of Variables Used}

\begin{tabular}{|c|c|c|}
\hline Variable & Definition & Source \\
\hline $\begin{array}{l}\text { Per capita } \\
\text { income } \\
\text { measures } \\
(\text { GDP) }\end{array}$ & $\begin{array}{l}\text { GDP is the sum of gross value added by all resident producers in the } \\
\text { economy plus any product taxes and minus any subsidies not included in } \\
\text { the value of the products. It is calculated without making deductions for } \\
\text { depreciation of fabricated assets or for depletion and degradation of } \\
\text { natural resources. Data are in constant } 1995 \text { U.S. \$. Dollar figures for } \\
\text { GDP are converted from domestic currencies using } 1995 \text { official } \\
\text { exchange rates. From the GDP per capita data we have computed the } \\
\text { growth rates by taking the log differences for the relevant period. }\end{array}$ & $\begin{array}{l}\text { World Bank } \\
\text { Development } \\
\text { Indicators [2002] }\end{array}$ \\
\hline $\begin{array}{l}\text { Gross } \\
\text { enrolment in } \\
\text { education }\end{array}$ & $\begin{array}{l}\text { The total number of pupils enrolled at primary and secondary level in } \\
\text { public and private schools. }\end{array}$ & Barro [1991] \\
\hline $\begin{array}{l}\text { Life } \\
\text { expectancy }\end{array}$ & $\begin{array}{l}\text { The number of years a newborn infant would live if prevailing patterns of } \\
\text { mortality at the time of its birth were to stay the same throughout its life. }\end{array}$ & $\begin{array}{l}\text { World Bank } \\
\text { Development } \\
\text { Indicators [2002] }\end{array}$ \\
\hline Fertility & $\begin{array}{l}\text { The number of children that would be born to a woman if she were to } \\
\text { live to the end of her childbearing years and bear children in accordance } \\
\text { with prevailing age-specific fertility rates. }\end{array}$ & $\begin{array}{l}\text { World Bank } \\
\text { Development } \\
\text { Indicators [2002] }\end{array}$ \\
\hline $\begin{array}{l}\text { Fractionali- } \\
\text { zation }\end{array}$ & $\begin{array}{l}\text { The fractionalization data are measuring the percentage of foreign } \\
\text { population (ethnic), of non-domestic languages and religion in a country } \\
\text { in a particular available year (mostly in the 1980s and 1990s). See } \\
\text { http://www.stanford.edu/ wacziarg/downloads/for the data. }\end{array}$ & Alesina et al. [2003] \\
\hline $\begin{array}{l}\text { Health } \\
\text { expenditures }\end{array}$ & $\begin{array}{l}\text { The sum of public and private health expenditures as a percentage of } \\
\text { GDP. It covers the provision of health services (preventive and curative), } \\
\text { family planning activities, nutrition activities, and emergency aid } \\
\text { designated for health but does not include provision of water and } \\
\text { sanitation. }\end{array}$ & $\begin{array}{l}\text { World Bank } \\
\text { Development } \\
\text { Indicators [2002] }\end{array}$ \\
\hline Immunization & $\begin{array}{l}\text { Child immunization measures the rate of vaccination coverage of } \\
\text { children under one year of age. }\end{array}$ & $\begin{array}{l}\text { World Bank } \\
\text { Development } \\
\text { Indicators [2002] }\end{array}$ \\
\hline $\begin{array}{l}\text { Exports and } \\
\text { imports }\end{array}$ & $\begin{array}{l}\text { Exports (Imports) of goods and services represent the value of all goods } \\
\text { and other market services exported (received) to (from) the rest of the } \\
\text { world. They include the value of merchandise, freight, insurance, } \\
\text { transport, travel, royalties, license fees, and other services, such as } \\
\text { communication, construction, financial, information, business, personal, } \\
\text { and government services. They exclude labor and property income } \\
\text { (formerly called factor services) as well as transfer payments. }\end{array}$ & $\begin{array}{l}\text { World Bank } \\
\text { Development } \\
\text { Indicators [2002] }\end{array}$ \\
\hline $\mathrm{M}_{2}$ & $\begin{array}{l}\text { The sum of currency outside banks, demand deposits other than those of } \\
\text { the central government, and the time, savings, and foreign currency } \\
\text { deposits of resident sectors other than the central government. It } \\
\text { corresponds to lines } 34 \text { and } 35 \text { in the International Monetary Fund's } \\
\text { (IMF) International Financial Statistics (IFS). }\end{array}$ & $\begin{array}{l}\text { World Bank } \\
\text { Development } \\
\text { Indicators [2002] }\end{array}$ \\
\hline Labor force & $\begin{array}{l}\text { People who meet the International Labour Organization (ILO) definition } \\
\text { of the economically active population: all people who supply labor for } \\
\text { the production of goods and services during a specified period. It } \\
\text { includes both the employed and the unemployed. }\end{array}$ & $\begin{array}{l}\text { World Bank } \\
\text { Development } \\
\text { Indicators [2002] }\end{array}$ \\
\hline Investment & $\begin{array}{l}\text { Price level of investment goods in 1960. Data are in constant } 1995 \text { U.S. } \\
\$ \text {. }\end{array}$ & $\begin{array}{l}\text { World Bank } \\
\text { Development } \\
\text { Indicators [2002] }\end{array}$ \\
\hline $\begin{array}{l}\text { Infectious } \\
\text { diseases }\end{array}$ & $\begin{array}{l}\text { The disease variables are defined as the number of death through a } \\
\text { certain disease as a percentage of the population in a country. See } \\
\text { http://www3.who.int/whosis/menu.cfm?path=whosis,mort\&language=en } \\
\text { glish. }\end{array}$ & $\begin{array}{l}\text { World Health } \\
\text { Organization; } \\
\text { Mortality Database }\end{array}$ \\
\hline $\begin{array}{l}\text { Tropical area } \\
\text { information }\end{array}$ & $\begin{array}{l}\text { Proportion of country's land area within geographical tropics. } \\
\text { Proportion of country's population living in geographical tropics. } \\
\text { Fraction tropical climate zone. }\end{array}$ & $\begin{array}{l}\text { Gallup, Mellinger } \\
\text { and Sachs } \\
\text { [2001] }\end{array}$ \\
\hline
\end{tabular}




\section{Table AII \\ Ultimatum Games}

\begin{tabular}{|c|c|}
\hline Country & Reference \\
\hline Czech Republic & $\begin{array}{l}\text { Babicky, Vitezslav and Andreas Ortmann, "Fairness in Risky Environments: (Theory and) } \\
\text { Evidence," Working Paper, Charles University, } 2005 .\end{array}$ \\
\hline Brazil & $\begin{array}{l}\text { Bianchi, A.M, “Are Brazilian Economists Different?,” Revista Brasileira de Economia, LII } \\
\text { (1998), 427-39. }\end{array}$ \\
\hline India & $\begin{array}{l}\text { Boarini, R., J. Laslier, and S. Robin, "Interpersonal Comparison of Utility in Bargaining: } \\
\text { Evidence from a Transcontinental Ultimatum Game," Working Paper, Ecole Polytechnique, } \\
2002 .\end{array}$ \\
\hline Russia & $\begin{array}{l}\text { Botelho, A., M.A. Hirsh, and E.E. Rutstrom, "Culture, Nationality and Demographics in } \\
\text { Ultimatum Games," Working Paper, Universidade do Minho, } 2000 .\end{array}$ \\
\hline China & $\begin{array}{l}\text { Chuah, S., R. Hoffmann, M. Jones, and G. Williams, "Do Cultures Clash? Evidence from } \\
\text { Cross-National Ultimatum Game Experiments," Working Paper, Nottingham University } \\
\text { Business School, } 2004 .\end{array}$ \\
\hline United Kingdom & $\begin{array}{l}\text { Chuah, S., R. Hoffmann, M. Jones, and G. Williams, "Do Cultures Clash? Evidence from } \\
\text { Cross-National Ultimatum Game Experiments," Working Paper, Nottingham University } \\
\text { Business School, 2004. }\end{array}$ \\
\hline Sweden & $\begin{array}{l}\text { Ellingsen, T., and M. Johannesson, "Sunk Costs, Fairness, and Disagreement," Working } \\
\text { Paper, Stockholm University, } 2003 .\end{array}$ \\
\hline Netherlands & $\begin{array}{l}\text { Gneezy, U., and W. Guth, "On Competing Reward Standards: An Experimental Study of } \\
\text { Ultimatum Bargaining," Journal of Socio-Economics, XXXI (2003), 599-607. }\end{array}$ \\
\hline Spain & $\begin{array}{l}\text { Grosskopf, B., "Reinforcement and Directional Learning in the Ultimatum Game with } \\
\text { Responder Competition," Experimental Economics, VI (2003), 141-158. }\end{array}$ \\
\hline Indonesia & $\begin{array}{l}\text { Henrich, J., R. Boyd, S. Bowles, C.F. Camerer, E. Fehr, H. Gintis, R. McElreath, M. } \\
\text { Alvard, A. Barr, J. Ensminger, K. Hill, F. Gil-White, M. Gurven, F. Marlowe, J.Q. Patton, } \\
\text { N. Smith, and D. Tracer, ““Economic Man” in Cross-Cultural Perspective: Behavioral } \\
\text { Experiments in } 15 \text { Small-Scale Societies,” Working Paper, Santa Fe Institute, } 2001 .\end{array}$ \\
\hline Kenya & $\begin{array}{l}\text { Henrich, J., R. Boyd, S. Bowles, C.F. Camerer, E. Fehr, H. Gintis, R. McElreath, M. } \\
\text { Alvard, A. Barr, J. Ensminger, K. Hill, F. Gil-White, M. Gurven, F. Marlowe, J.Q. Patton, } \\
\text { N. Smith, and D. Tracer, “"Economic Man” in Cross-Cultural Perspective: Behavioral } \\
\text { Experiments in } 15 \text { Small-Scale Societies,” Working Paper, Santa Fe Institute, } 2001 .\end{array}$ \\
\hline Mongolia & $\begin{array}{l}\text { Henrich, J., R. Boyd, S. Bowles, C.F. Camerer, E. Fehr, H. Gintis, R. McElreath, M. } \\
\text { Alvard, A. Barr, J. Ensminger, K. Hill, F. Gil-White, M. Gurven, F. Marlowe, J.Q. Patton, } \\
\text { N. Smith, and D. Tracer, “"Economic Man” in Cross-Cultural Perspective: Behavioral } \\
\text { Experiments in } 15 \text { Small-Scale Societies,”Working Paper, Santa Fe Institute, } 2001 .\end{array}$ \\
\hline Zinbabwe & $\begin{array}{l}\text { Henrich, J., R. Boyd, S. Bowles, C.F. Camerer, E. Fehr, H. Gintis, R. McElreath, M. } \\
\text { Alvard, A. Barr, J. Ensminger, K. Hill, F. Gil-White, M. Gurven, F. Marlowe, J.Q. Patton, } \\
\text { N. Smith, and D. Tracer, ““Economic Man” in Cross-Cultural Perspective: Behavioral } \\
\text { Experiments in } 15 \text { Small-Scale Societies,” Working Paper, Santa Fe Institute, } 2001 .\end{array}$ \\
\hline France & $\begin{array}{l}\text { Munier, B., and C. Zaharia, "High Stakes and Acceptance Behavior in Ultimatum } \\
\text { Bargaining: A Contribution from an International Experiment," Theory and Decision, LIII } \\
\text { (2003), 187-207. }\end{array}$ \\
\hline Romania & $\begin{array}{l}\text { Munier, B., and C. Zaharia, "High Stakes and Acceptance Behavior in Ultimatum } \\
\text { Bargaining: A Contribution from an International Experiment," Theory and Decision, LIII } \\
\text { (2003), 187-207. }\end{array}$ \\
\hline Austria & $\begin{array}{l}\text { Okada, A., and A. Riedl, "When Culture Does Not Matter: Experimental Evidence from } \\
\text { Coalition Formation Ultimatum Games in Austria and Japan," Working Paper, University } \\
\text { of Amsterdam, } 1999 .\end{array}$ \\
\hline Canada & $\begin{array}{l}\text { Oxoby, R.J., and K.N. McLeish, "Sequential Decision and Strategy Vector Methods in } \\
\text { Ultimatum Bargaining: Evidence on the Strength of Other-Regarding Behavior," Working } \\
\text { Paper, University of Calgary, } 2004 .\end{array}$ \\
\hline Germany & $\begin{array}{l}\text { Poulsen, A.U., and J.H.W. Tan, "Can Information Backfire? Experimental Evidence from } \\
\text { the Ultimatum Game," Working Paper, Aarhus School of Business, } 2004 .\end{array}$ \\
\hline Israel & $\begin{array}{l}\text { Roth, A.E., V. Prasnikar, M. Okuno-Fujiware, and S. Zamir, "Bargaining and Market } \\
\text { Behavior in Jerusalem, Ljubljana, Pittsburgh and Tokyo: An Experimental Study," } \\
\text { American Economic Review, LXXXI (1991), 1068-1095. }\end{array}$ \\
\hline Japan & Roth, A.E., V. Prasnikar, M. Okuno-Fujiware, and S. Zamir, "Bargaining and Market \\
\hline
\end{tabular}


Behavior in Jerusalem, Ljubljana, Pittsburgh and Tokyo: An Experimental Study," American Economic Review, LXXXI (1991), 1068-1095.

United States Roth, A.E., V. Prasnikar, M. Okuno-Fujiware, and S. Zamir, "Bargaining and Market Behavior in Jerusalem, Ljubljana, Pittsburgh and Tokyo: An Experimental Study," American Economic Review, LXXXI (1991), 1068-1095.

Yugoslavia Roth, A.E., V. Prasnikar, M. Okuno-Fujiware, and S. Zamir, "Bargaining and Market Behavior in Jerusalem, Ljubljana, Pittsburgh and Tokyo: An Experimental Study," American Economic Review, LXXXI (1991), 1068-1095.

Slovak Republic Slonim, R., and A.E. Roth, "Learning in High Stakes Ultimatum Games: An Experiment in the Slovak Republic,” Econometrica, CXVI (1998), 569-596. 


\section{Table AIII \\ Trust Games}

\begin{tabular}{|c|c|}
\hline Country & Reference \\
\hline South Africa & $\begin{array}{l}\text { Ashraf, N., I. Bohnet and N. Piankov, "Is Trust a Bad Investment?," Working Paper, John F. } \\
\text { Kennedy School of Government, Harvard University, } 2003 .\end{array}$ \\
\hline Zimbabwe & $\begin{array}{l}\text { Barr, A., "Trust and Expected Trustworthiness: Experimental Evidence from Zimbabwean } \\
\text { Villages," Economic Journal, CXIII (2003), 614-630. }\end{array}$ \\
\hline Netherlands & $\begin{array}{l}\text { Bellemare, C., and S. Kroger, "On Representative Trust," Working Paper, CentER, Tilburg } \\
\text { University, 2003. }\end{array}$ \\
\hline Belgium & $\begin{array}{l}\text { Bouckaert, J., and G. Dhaene, "Inter-Ethnic Trust and Reciprocity: Results of an Experiment } \\
\text { with Small Businessmen," European Journal of Political Economy, XX (2004), 869-886. }\end{array}$ \\
\hline Turkey & $\begin{array}{l}\text { Bouckaert, J., and G. Dhaene, "Inter-Ethnic Trust and Reciprocity: Results of an Experiment } \\
\text { with Small Businessmen," European Journal of Political Economy, XX (2004), 869-886. }\end{array}$ \\
\hline China & $\begin{array}{l}\text { Buchan, N.R., E.J. Johnson, and R.T.A. Croson, "Let's Get Personal: An International } \\
\text { Examination of the Influence of Communication, Culture and Social Distance on Other } \\
\text { Regarding Preferences," Journal of Economic Behavior and Organization, forthcoming. }\end{array}$ \\
\hline Japan & $\begin{array}{l}\text { Buchan, N.R., E.J. Johnson, and R.T.A. Croson, "Let's Get Personal: An International } \\
\text { Examination of the Influence of Communication, Culture and Social Distance on Other } \\
\text { Regarding Preferences," Journal of Economic Behavior and Organization, forthcoming. }\end{array}$ \\
\hline Korea & $\begin{array}{l}\text { Buchan, N.R., E.J. Johnson, and R.T.A. Croson, "Let's Get Personal: An International } \\
\text { Examination of the Influence of Communication, Culture and Social Distance on Other } \\
\text { Regarding Preferences," Journal of Economic Behavior and Organization, forthcoming. }\end{array}$ \\
\hline United States & $\begin{array}{l}\text { Buchan, N.R., E.J. Johnson, and R.T.A. Croson, "Let's Get Personal: An International } \\
\text { Examination of the Influence of Communication, Culture and Social Distance on Other } \\
\text { Regarding Preferences," Journal of Economic Behavior and Organization, forthcoming. }\end{array}$ \\
\hline Colombia & $\begin{array}{l}\text { Cardenas, J.C. (2003). En vos confio: an experimental exploration on the micro-foundations of } \\
\text { trust, reciprocity and social distance in Colombia. Working Paper, Universidad de Los Andes, } \\
\text { Economics Department. }\end{array}$ \\
\hline Brazil & $\begin{array}{l}\text { Csukás, C., P. Fracalanza, T. Kovács, and M. Willinger, "Stated Trust versus Behavior in an } \\
\text { Intercultural Experiment," Working Paper 2003-25, Technical University of Budapest, } 2003 .\end{array}$ \\
\hline Greece & $\begin{array}{l}\text { Csukás, C., P. Fracalanza, T. Kovács, and M. Willinger, "Stated Trust versus Behavior in an } \\
\text { Intercultural Experiment," Working Paper } 2003-25 \text {, Technical University of Budapest, } 2003 .\end{array}$ \\
\hline Hungary & $\begin{array}{l}\text { Csukás, C., P. Fracalanza, T. Kovács, and M. Willinger, "Stated Trust versus Behavior in an } \\
\text { Intercultural Experiment," Working Paper 2003-25, Technical University of Budapest, } 2003 .\end{array}$ \\
\hline Russia & $\begin{array}{l}\text { Csukás, C., P. Fracalanza, T. Kovács, and M. Willinger, "Stated Trust versus Behavior in an } \\
\text { Intercultural Experiment," Working Paper 2003-25, Technical University of Budapest, } 2003 .\end{array}$ \\
\hline Israel & $\begin{array}{l}\text { Fershtman, C., and U. Gneezy, "Discrimination in a Segmented Society: An Experimental } \\
\text { Approach," Quarterly Journal of Economics, CXVI (2001), 351-377. }\end{array}$ \\
\hline Kenya & $\begin{array}{l}\text { Greig, F., and I. Bohnet, "Is There Reciprocity in a Reciprocal Exchange Economy? Evidence } \\
\text { from a Slum in Nairobi, Kenya," Working Paper, JFK School of Government, } 2005 .\end{array}$ \\
\hline Sweden & $\begin{array}{l}\text { Holm, H.J., and A. Danielson, "Tropic Trust versus Nordic Trust: Experimental Evidence from } \\
\text { Tanzania and Sweden," Economic Journal, CXV (2005), 505-532. }\end{array}$ \\
\hline Bulgaria & $\begin{array}{l}\text { Koford, K., "Experiments on Trust and Bargaining in Bulgaria: The Effects of Institutions and } \\
\text { Culture," Working Paper, University of Delaware, } 2003 .\end{array}$ \\
\hline Uganda & $\begin{array}{l}\text { Mosley, P., and A. Verschoor, "The Development of Trust and Social Capital in Rural Uganda: } \\
\text { An Experimental Approach," Working Paper, University of Sheffield, } 2005 .\end{array}$ \\
\hline France & $\begin{array}{l}\text { Willinger, M., C. Keser, C. Lohmann, and J. Usunier, "A Comparison of Trust and Reciprocity } \\
\text { between France and Germany: Experimental Investigation Based on the Investment Game," } \\
\text { Journal of Economic Psychology, XXIV (2003), 447-466. }\end{array}$ \\
\hline Germany & $\begin{array}{l}\text { Willinger, M., C. Keser, C. Lohmann, and J. Usunier, "A Comparison of Trust and Reciprocity } \\
\text { between France and Germany: Experimental Investigation Based on the Investment Game," } \\
\text { Journal of Economic Psychology, XXIV (2003), 447-466. }\end{array}$ \\
\hline
\end{tabular}


Figure I

The Workings of the Immune System and the Role of the MHC

(A)

Schematic Representation of HLA -A02 Showing the Four Domains with the Polymorphic $\alpha_{1}$ and $\alpha_{2}$ at the Top.
(B)

T Cell Response to Viral Infection and the Role of MHC Molecules in Presenting Peptides
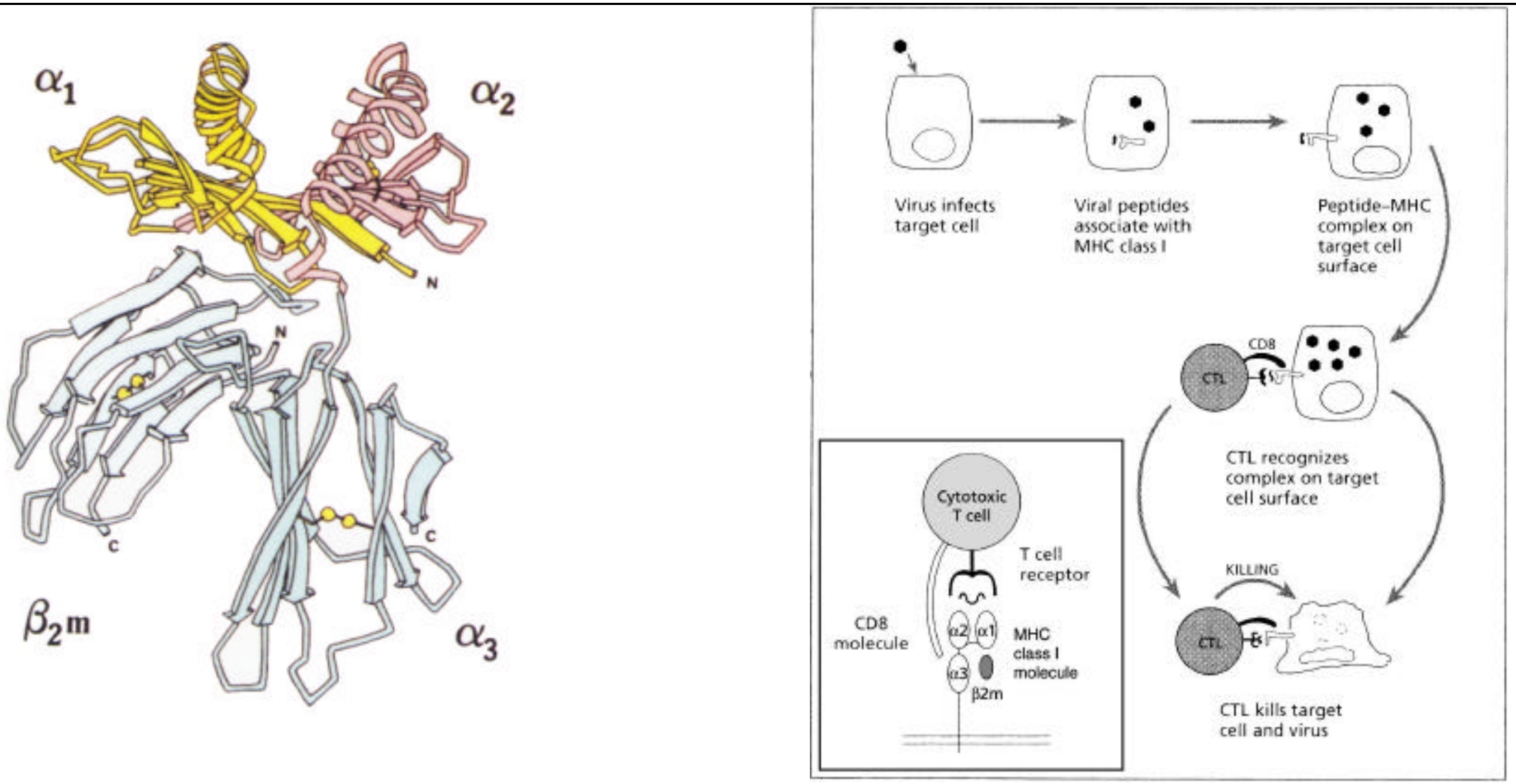
Figure II

Rank-Ordered Frequency Distribution of HLA-A and HLA-B in 63 Populations

\begin{tabular}{|c|c|}
\hline $\begin{array}{c}\text { (A) } \\
\text { HLA-A }\end{array}$ & $\begin{array}{c}\text { (B) } \\
\text { HLA-B }\end{array}$ \\
\hline 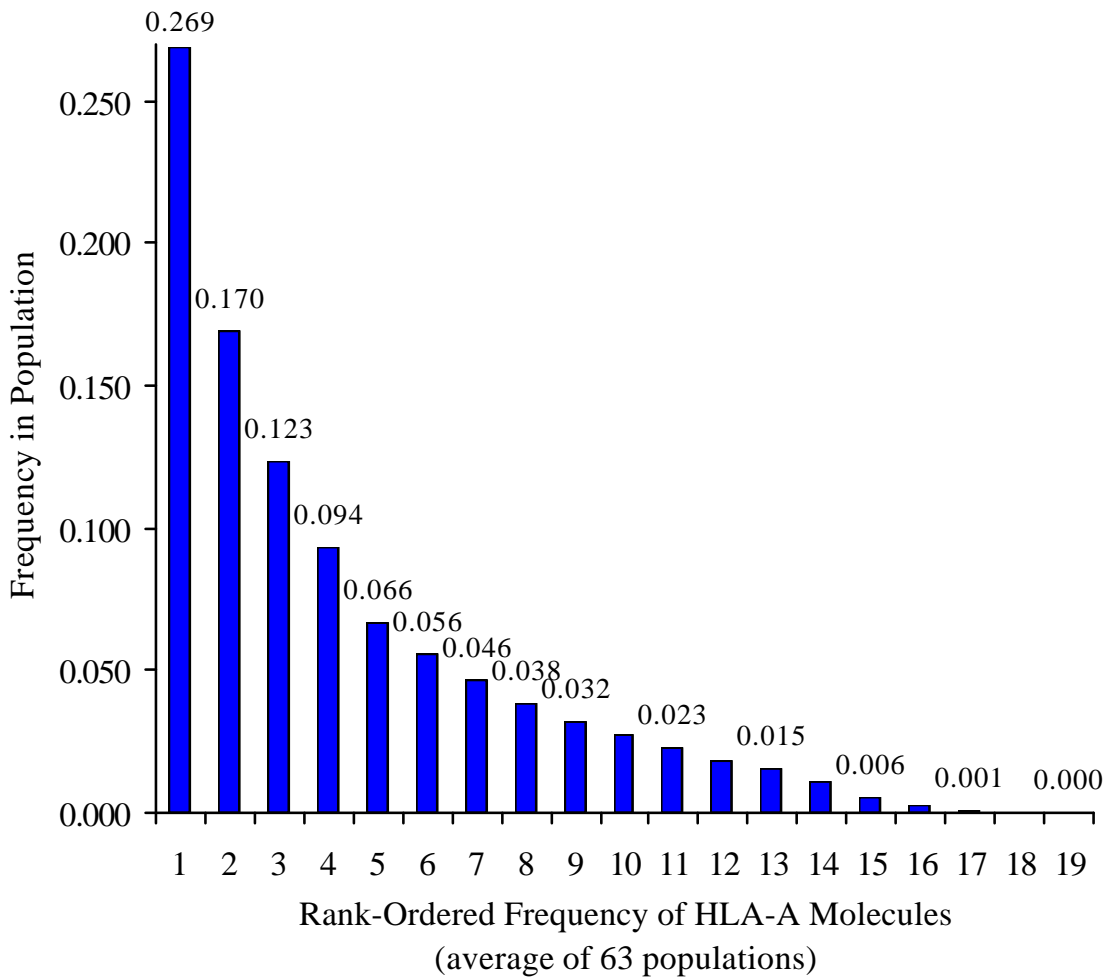 & (1) \\
\hline
\end{tabular}


Figure III

Frequency of HLA-A and HLA-B Alleles and Levels of Diversity

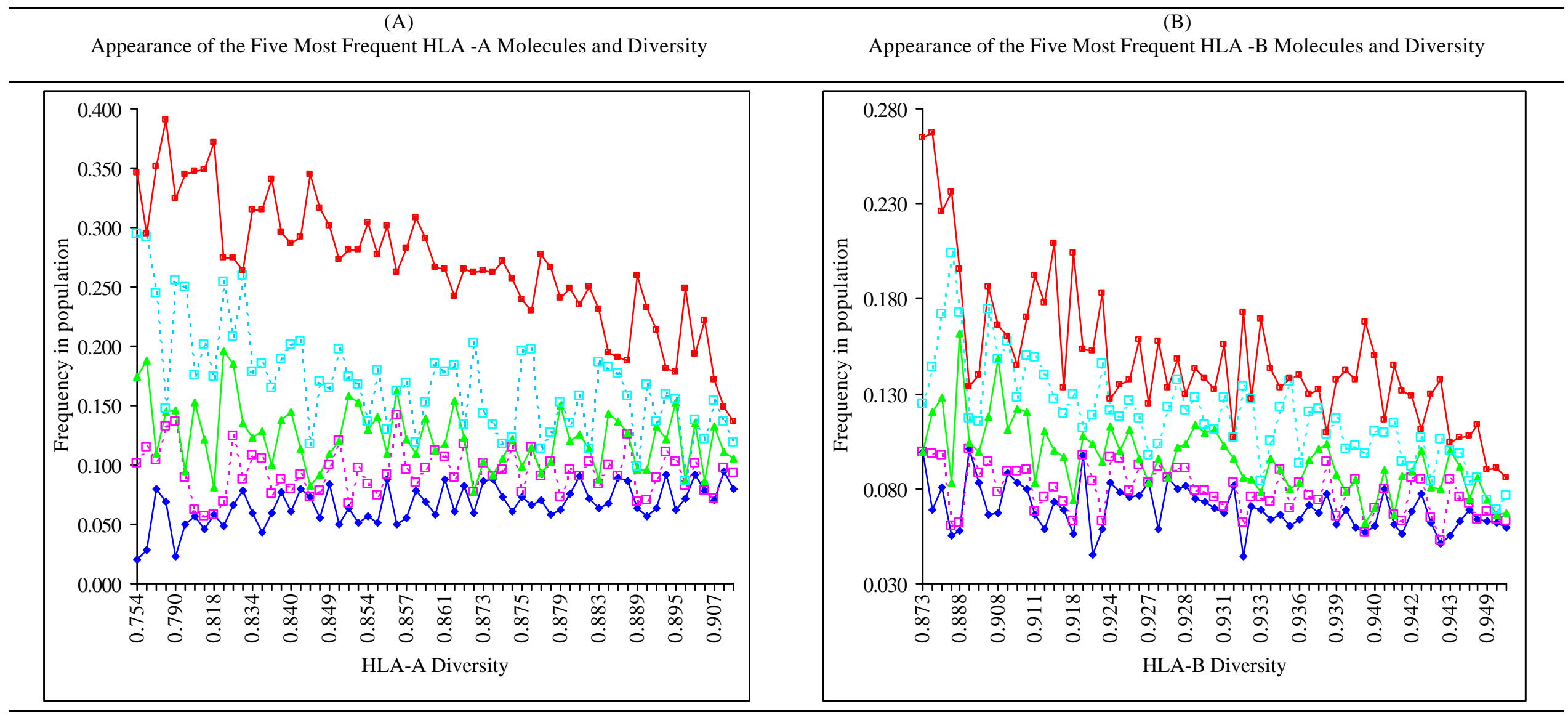


Figure IV

Simulation Results of Human Cooperation and MHC Diversity

(A)

Results for Two MHC Molecules

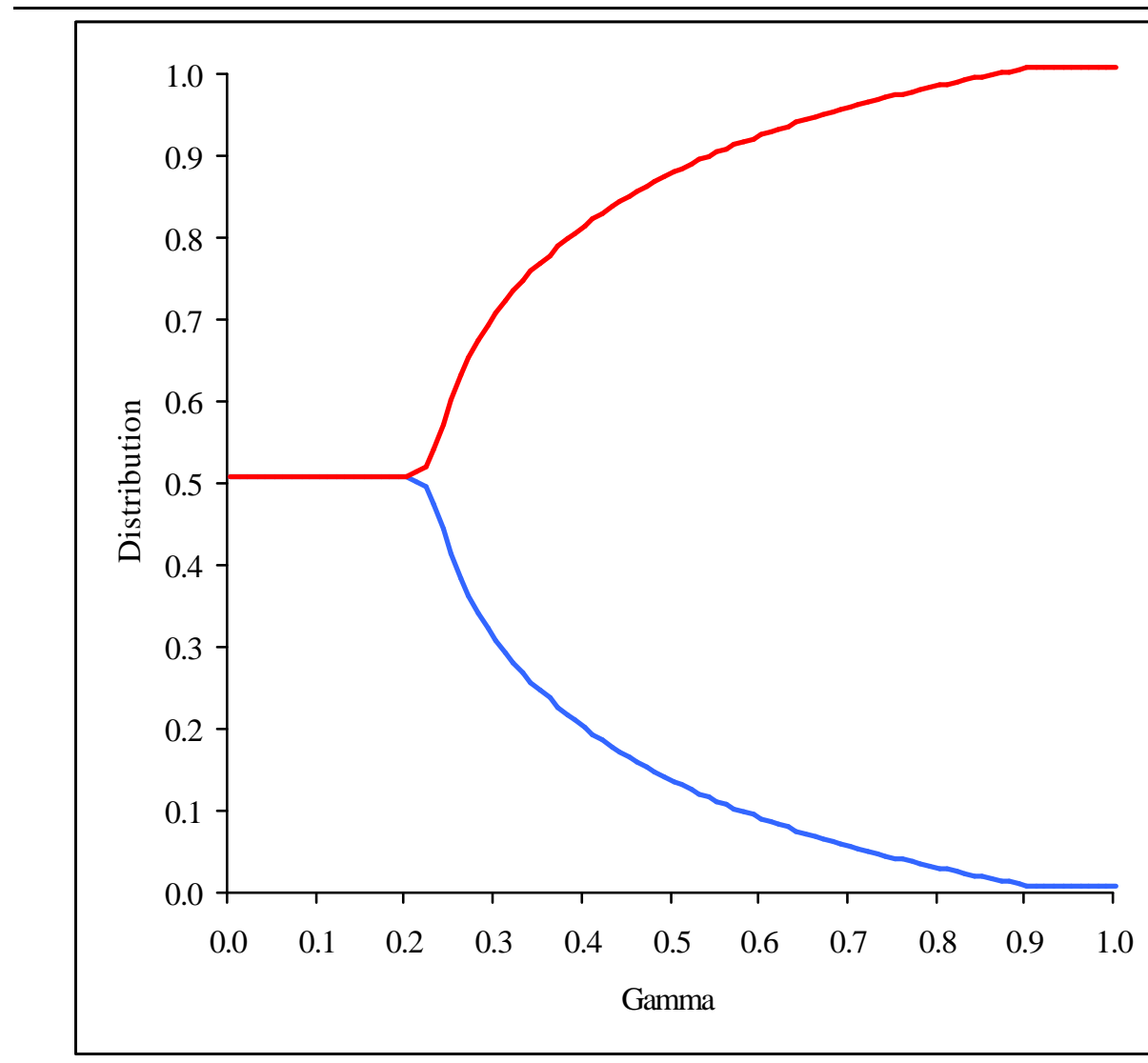

(B)

Results for Three MHC Molecules

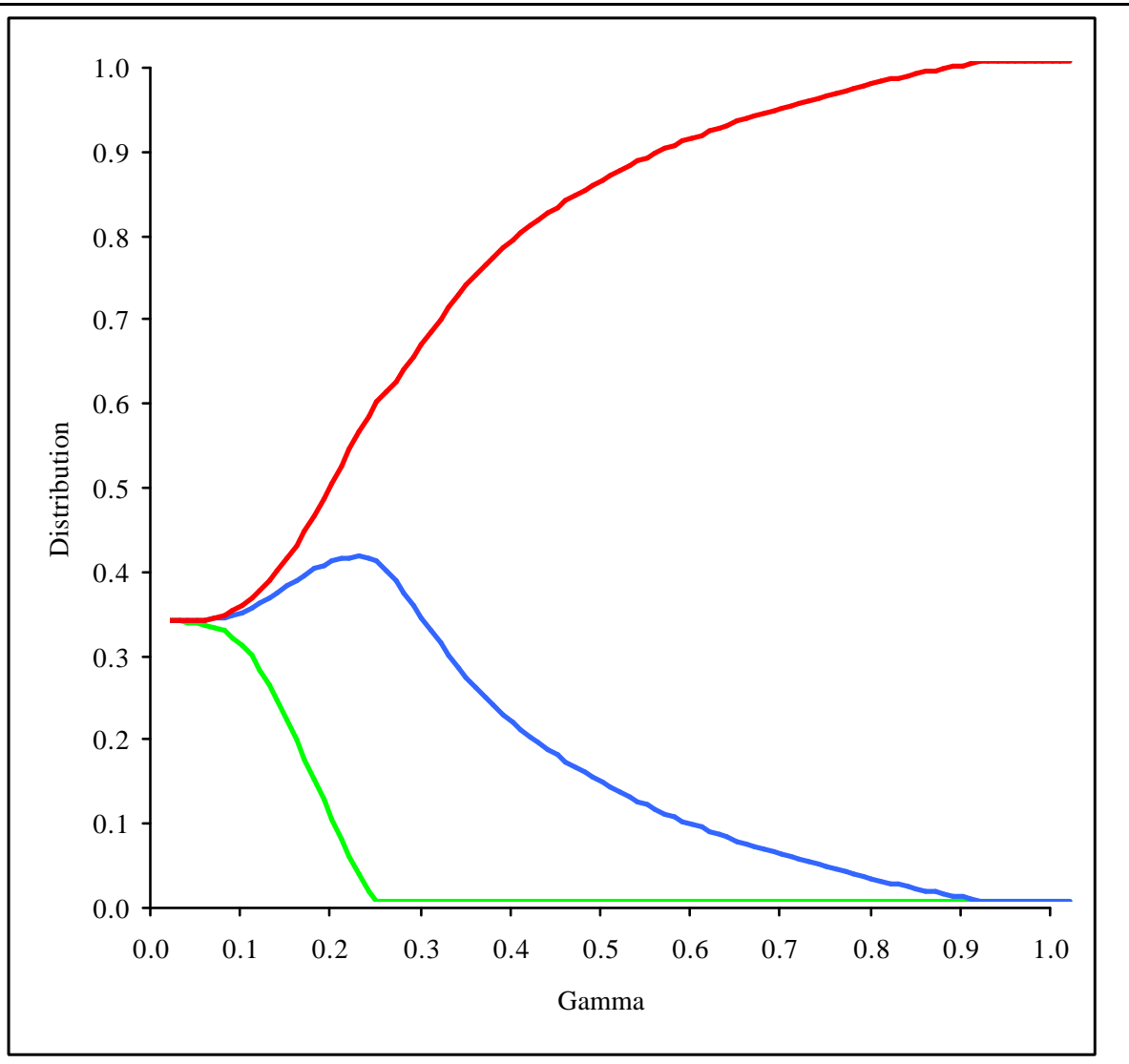

Note: We used the following parameters: $n=10, m=2$ (Panel A), $m=3$ (Panel B), $\bar{p}_{\text {low }}=0.1, \bar{p}_{\text {high }}=0.6, q_{\text {low }}=0.1, q_{\text {high }}=0.6$, and $\alpha=0.1$. 
Figure V

Ultimatum and Trust Games

\section{(A)}

Offer Rates in Ultimatum Games and HLA -A Diversity $(n=23)$

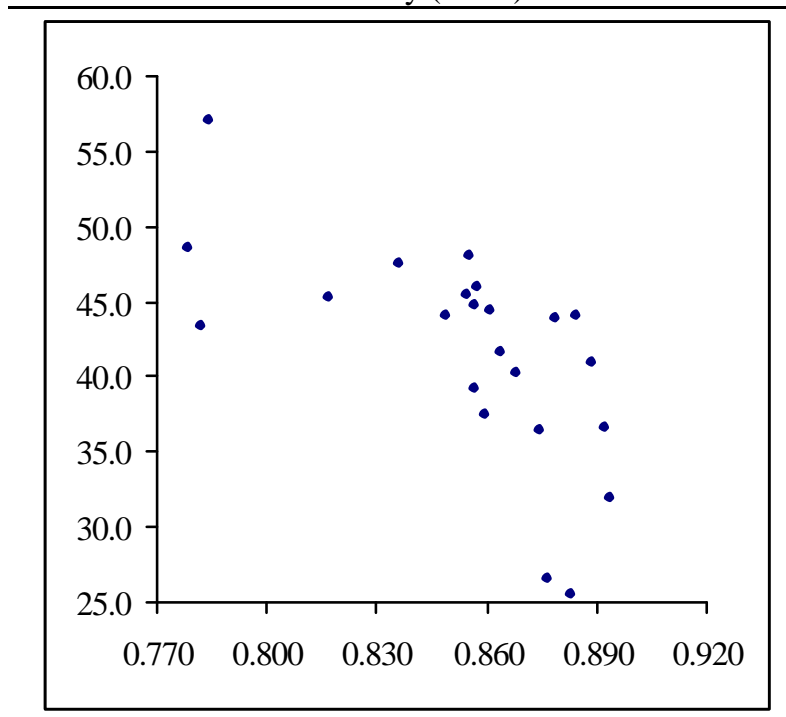

(C)

Shares of Money Sent in Trust Games and HLA -A Diversity $(n=22)$

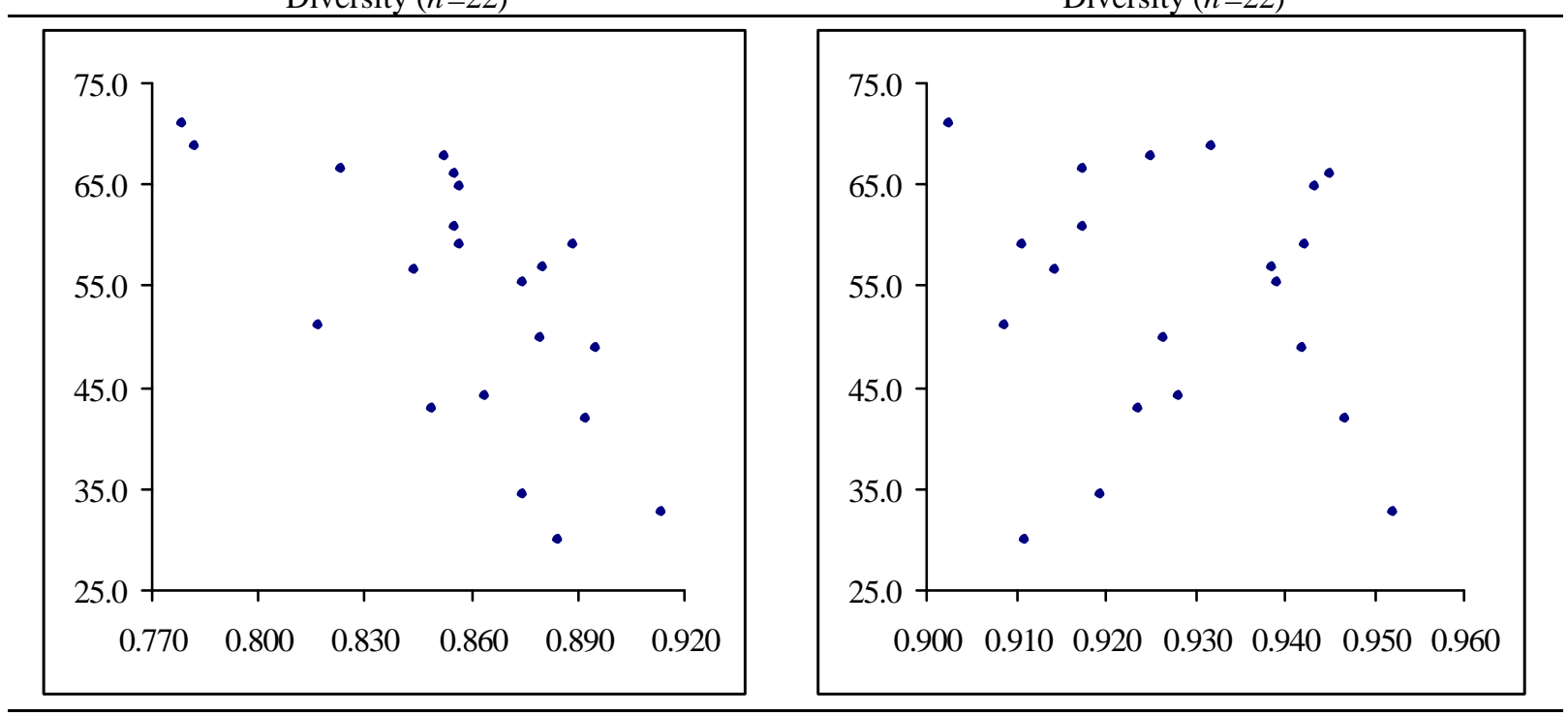

Note: The horizontal axis measures HLA -A diversity (Panel A and C) and HLA-B diversity (Panel B and D) and the vertical axis illustrates the offer rates in ultimatum games (Panel A and B) and the shares of money sent in trust games (Panel C and D). 
Figure VI

Health Outcomes and MHC Diversity

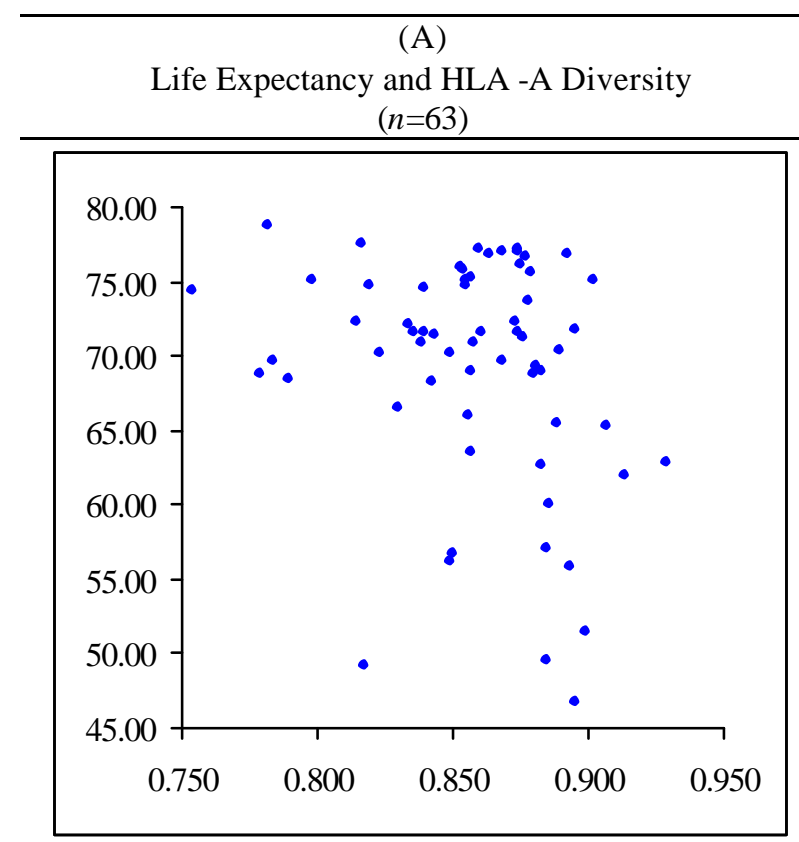

(C)

Fraction of the Population that Has Died from Infectious Viral Diseases (1,000s) and HLA -A Diversity

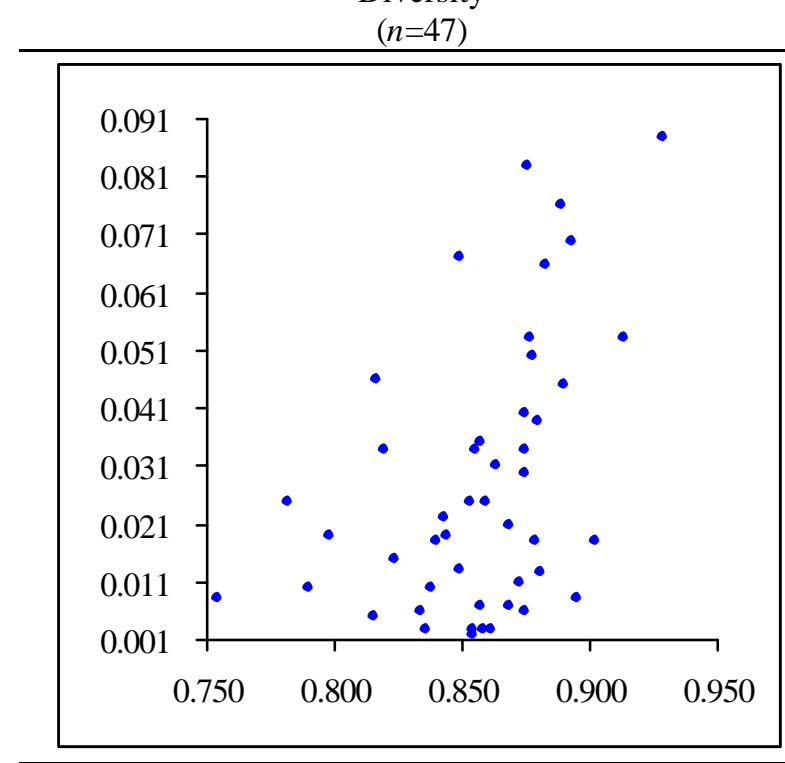

(B)

Life Expectancy and HLA -B Diversity $(n=63)$

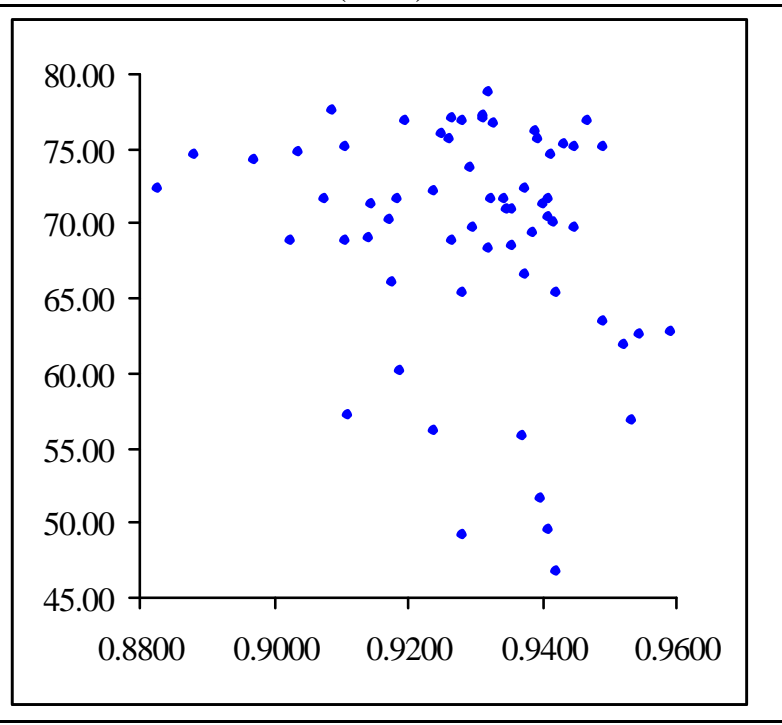

(D)

Fraction of the Population that Has Died from Infectious Viral Diseases (1,000s) and HLA -B Diversity $(n=47)$

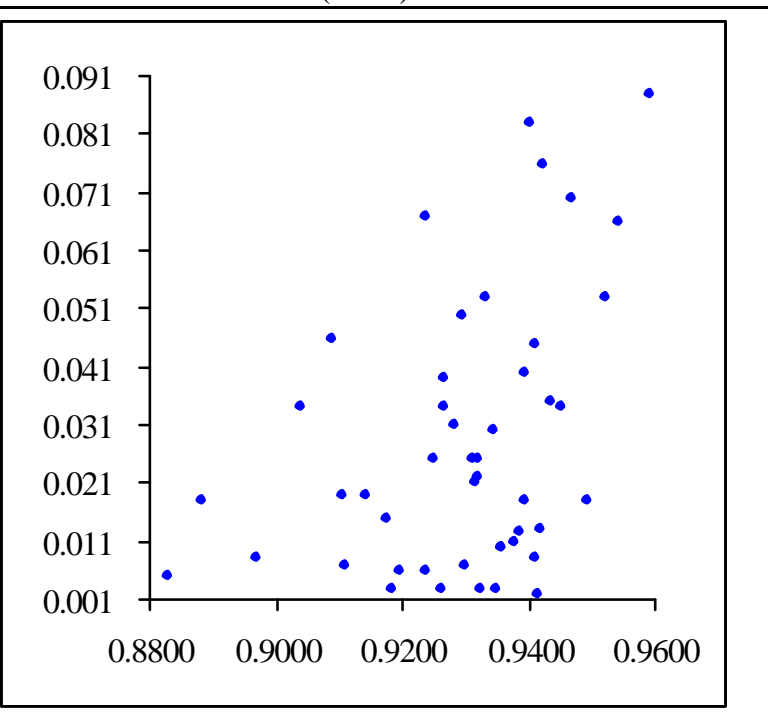

Note: Variables are defined in the Appendix. The horizontal axis measures HLA-A diversity (Panel A and C) and HLA-B diversity (Panel B and D) and the vertical axis illustrates life expectancy at birth (Panel A and B) and the fraction of the population that has died from viral infections (Panel C and D). 
Figure VII

HLA-A and HLA-B Diversity and GDP per Capita Growth 1960-2000

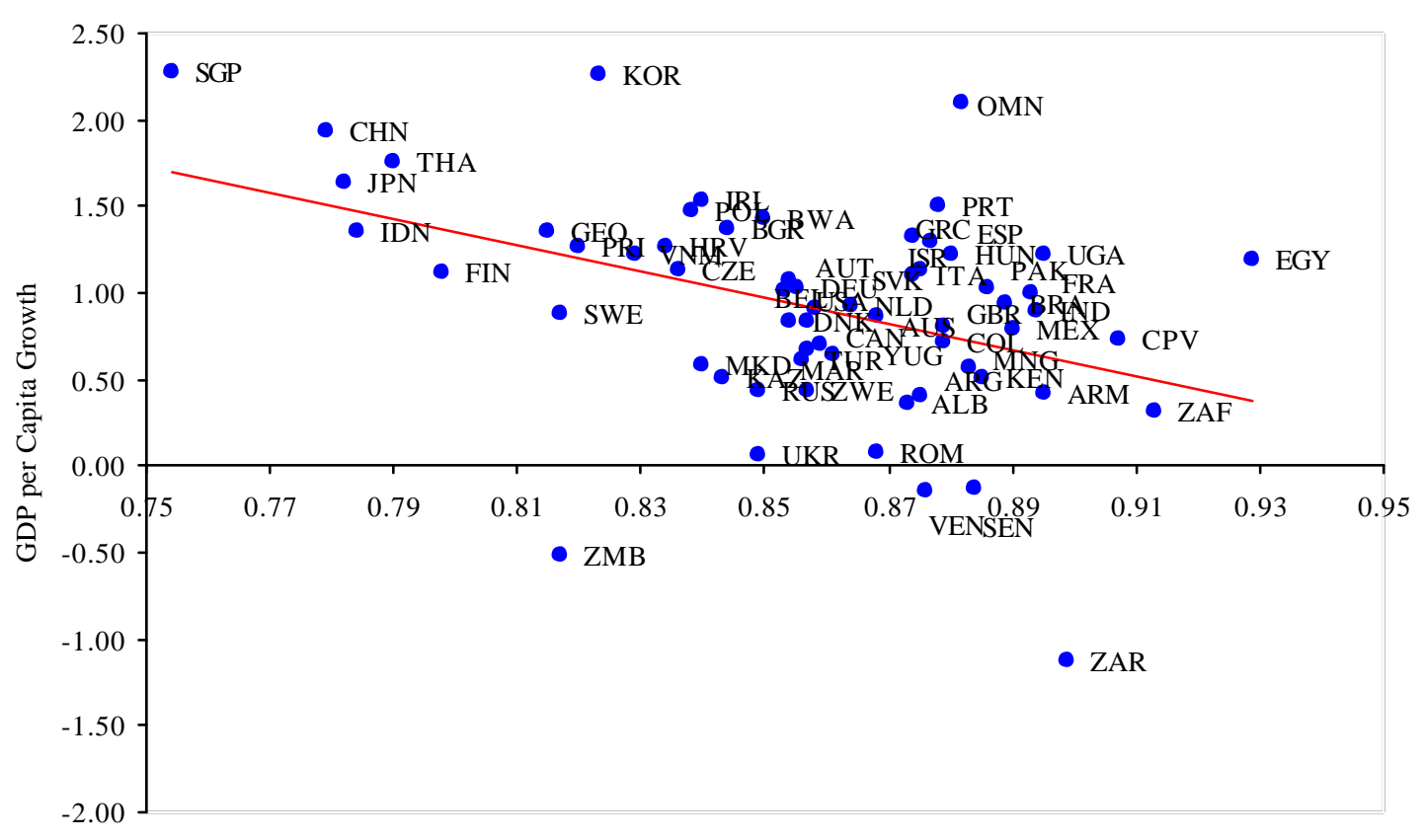

HLA-A Diversity

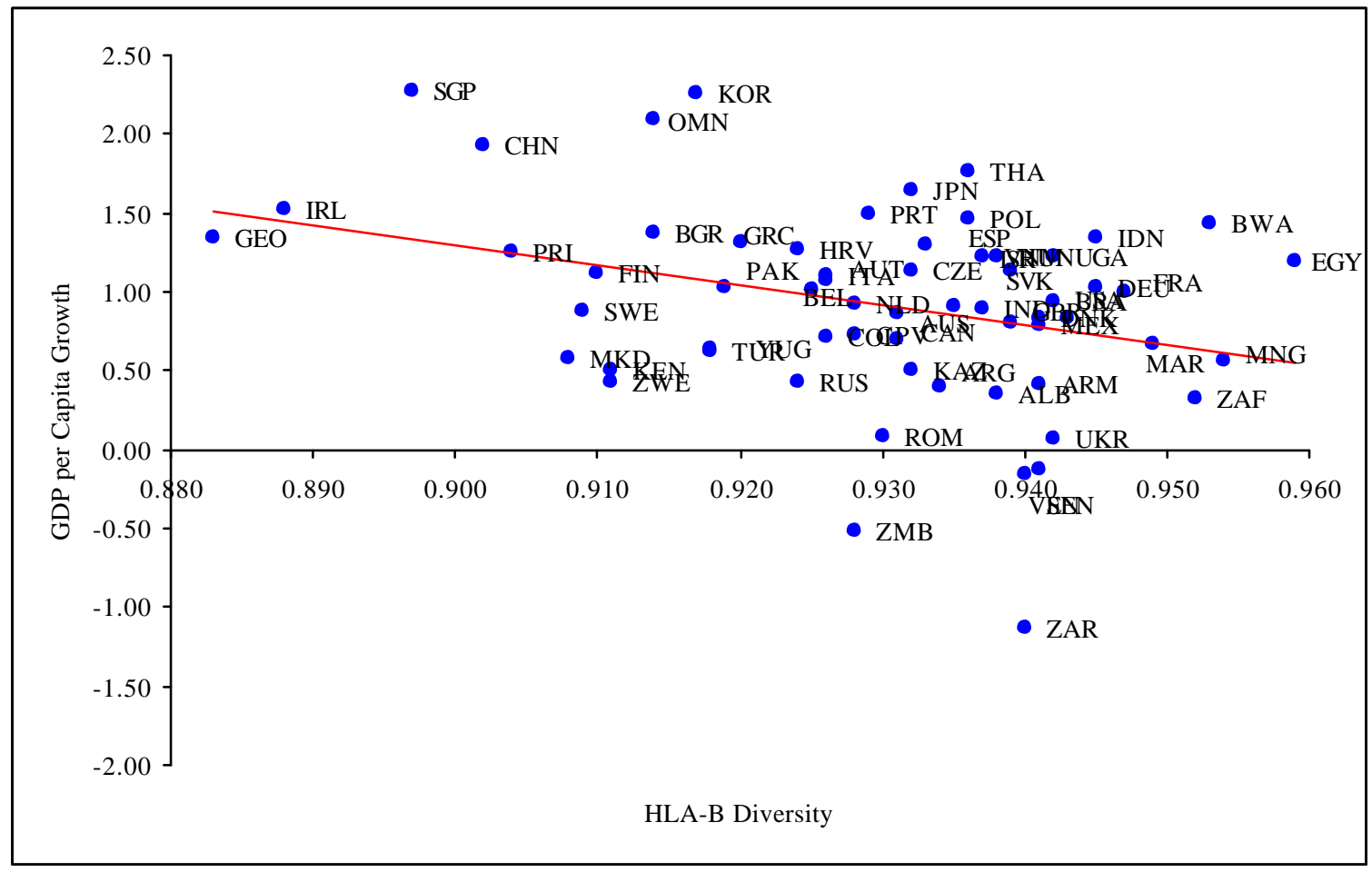

